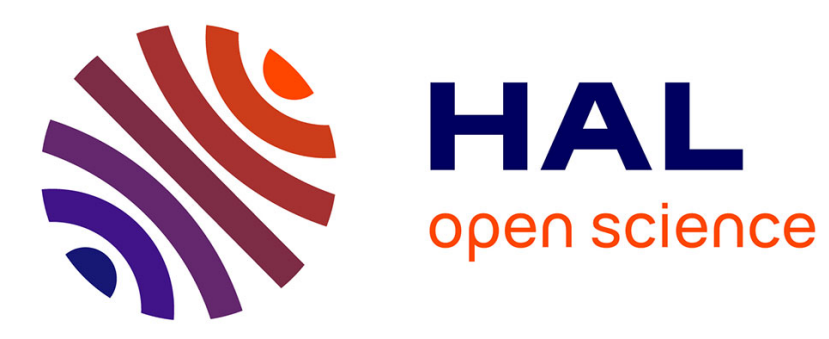

\title{
Fuel performances in Spark-Ignition (SI) engines: Impact of flame stretch
}

Pierre Brequigny, Fabien Halter, Christine Mounaïm-Rousselle, Thomas Dubois

\section{- To cite this version:}

Pierre Brequigny, Fabien Halter, Christine Mounaïm-Rousselle, Thomas Dubois. Fuel performances in Spark-Ignition (SI) engines: Impact of flame stretch. Combustion and Flame, 2016, 10.1016/j.combustflame.2016.01.005 . hal-01340392

\section{HAL Id: hal-01340392 \\ https://hal.science/hal-01340392}

Submitted on 20 Mar 2019

HAL is a multi-disciplinary open access archive for the deposit and dissemination of scientific research documents, whether they are published or not. The documents may come from teaching and research institutions in France or abroad, or from public or private research centers.
L'archive ouverte pluridisciplinaire HAL, est destinée au dépôt et à la diffusion de documents scientifiques de niveau recherche, publiés ou non, émanant des établissements d'enseignement et de recherche français ou étrangers, des laboratoires publics ou privés. 


\section{Fuel Performances in Spark-Ignition (SI)}

\section{Engines: Impact of Flame Stretch}

Pierre Brequigny $^{1,2,{ }^{*}}$, Fabien Halter ${ }^{1}$, Christine Mounaïm-Rousselle ${ }^{1}$, Thomas Dubois ${ }^{2}$

${ }^{1}$ Laboratoire PRISME, Université d'Orléans, INSA CVL, Orléans 45072, France

${ }^{2}$ Centre de Recherche de Solaize, TOTAL Marketing \& Services, Solaize, France

pierre.brequigny@univ-orleans.fr

christine.rousselle@,univ-orleans.fr

fabien.halter@,univ-orleans.fr

thomas.dubois@total.com

corresponding author: Pierre Bréquigny

Laboratoire PRISME, 8 Rue Léonard de Vinci - 45072 Orléans cedex 2, France

Phone : +33 238492421, E-mail : pierre.brequigny@univ-orleans.fr 


\begin{abstract}
In a context of decreasing pollutant emissions, the transport sector is having to tackle improvements to the engine concept as well as fuel diversification. The use of these different fuels often has an impact on the combustion performance itself. In the case of Spark Ignition (SI) engines, efficiency is a function of the combustion speed, i.e. the speed at which the fresh air-fuel mixture is consumed by the flame front. Every expanding flame is subject to flame curvature and strain rate, which both contribute to flame stretch. As each air-fuel mixture responds differently to flame stretch, this paper focuses on understanding the impact of flame stretch on fuel performances in SI engines. Different air-fuel mixtures (different fuels or equivalence ratios) with similar unstretched laminar burning speeds and thermodynamic properties but different responses to stretch were selected. The mixtures were studied in a turbulent spherical vessel and in an optical engine using Mie-Scattering tomography. The combustion phasing was also investigated in both optical and all-metal single cylinder engines. Results show that flame stretch sensitivity properties such as Markstein length and Lewis number, determined in laminar combustion conditions, are relevant parameters that need to be taken into consideration to predict the global performance of fuels, either experimentally or for modeling simulation.
\end{abstract}

Keywords: flame stretch; premixed combustion; Spark-Ignition engine.

\title{
Introduction
}

Nowadays, the automotive industry is facing a context of fuel diversification. Due to the increasingly restrictive standards on pollutants and $\mathrm{CO}_{2}$ emissions, the car industry is developing new technologies that impact fuel development. Moreover to compensate for the depletion of fossil energy resources, oil companies have introduced Biofuels, used either pure or blended. The use of these fuels in a Spark-Ignition (SI) engine may induce a different combustion behavior and could 
therefore impact engine efficiency. To improve their products, oil companies seek to develop fuels that burn fast, evaporate easily, and have a high resistance to knock. For SI engines, the efficiency can be directly improved by increasing the area of the high-pressure loop on the P-V diagram and therefore by increasing the flame speed. The fundamental laminar burning speed $S_{L}{ }^{0}$ is hence usually investigated as the first step in evaluating potential alternative fuels for SI engines [1-4]. Moreover it is a key parameter for combustion modeling in SI engines since the $S_{L}{ }^{0}$ value is required in most existing models [5-10]. This burning speed corresponds to the speed of a onedimensional planar adiabatic flame in laminar conditions without any instability and is a function of pressure, temperature, fuel and equivalence ratio. Nevertheless, $S_{L}{ }^{0}$ cannot be considered as the speed of an expanding flame since expanding flames are subject to flame stretch, which is a compound of strain rate and flame curvature [11]. The flame stretch can be defined as the relative growth rate of the flame surface $A[12]$ :

$$
K=\frac{1}{A} \frac{d A}{d t}
$$

Initially presented in the work of Karlovitz et al. [13] and Markstein [14], flame stretch is usually linearly linked [15] to the laminar flame speed $S_{b}$ as below, with $L_{b}$ the Markstein length and $S_{b}{ }^{0}$ the unstretched laminar flame speed:

$$
S_{b}=S_{b}^{0}-L_{b} K
$$

In some recent studies, a more realistic nonlinear relationship between flame speed and flame stretch has been used [16-18]:

$$
\left(\frac{S_{b}}{S_{b}^{0}}\right)^{2} \ln \left(\frac{S_{b}}{S_{b}^{0}}\right)^{2}=-\frac{2 L_{b} K}{S_{b}^{0}}
$$


Under certain assumptions the unstretched laminar flame speed, $S_{b}{ }^{0}$ is directly related to $S_{L}{ }^{0}$ by using the expansion ratio $\rho_{b} / \rho_{u}$, where $\rho_{b}$ and $\rho_{u}$ are respectively the burnt and fresh gas densities:

$$
S_{L}^{0}=\frac{\rho_{b}}{\rho_{u}} S_{b}^{0}
$$

In equations (2) and (3), the Markstein length $L_{b}$ is a key parameter because it represents the flame stretch sensitivity of an air-fuel mixture. It is a function of the Zeldovich number, the flame thickness and particularly of the Lewis number Le (i.e. the ratio of the thermal diffusivity to the mass diffusivity). As the two parameters $L_{b}$ and $L e$ are strongly dependent on the fuel, the different responses of fuels to flame stretch will impact the flame propagation differently. While this effect has been fully investigated in laminar conditions [19-21] and even in turbulent conditions [22-24], only a few recent studies have addressed the effect of flame stretch in an SI engine [25-27]. Aleiferis et al. [25] compared methane, ethanol, butanol, iso-octane and gasoline flame propagation in an optical SI engine. Their results showed different flame radius evolutions and a ranking of the four mixtures in terms of Markstein lengths. The mixtures with the lowest Markstein lengths appeared to be those with the highest flame growth speed. However since the mixtures were studied at the same equivalence ratio, they present different unstretched laminar flame speeds. It could not be concluded from this study therefore whether the propagation differences were due to the flame stretch response rather than to a laminar flame speed ranking. Most CFD models require the unstretched laminar burning speed $S_{L}^{0}[5,7,8,28]$, often calculated by using correlations such as those of Metghalchi and Keck [29] or Gülder [30]. However, only a few models take into account the laminar flame speed dependence on the flame stretch with respect to the Markstein length or the Lewis number of the fuel-air mixture and use a stretched burning speed $[6,7,9,10,31]$. For instance, Dahms et al. $[9,10]$ recently developed the SparkCIMM model. This model is based on 
the G-equation developments by Peters [7] in which the turbulent flame speed needs to be modeled. Dahms et al. proposed a model where the turbulent flame speed is computed from the stretched laminar burning speed calculated with a linear relation expressed by equation (2) and the model of Clavin [15].

To gain a better understanding of the impact of flame stretch on fuel combustion performance in SI engines and to assess how the different flame stretch responses of the mixtures can impact engine performance, an original experimental approach has been used here, covering numerous configurations from the simplest, a laminar spherical combustion vessel, to the most complicated, an all-metal single cylinder SI Engine. The objectives of this study are then:

- to assess what is the consequence of the various flame stretch responses, i.e. the Markstein lengths of different mixtures on the flame propagation in a turbulent vessel at atmospheric pressure;

- to verify if the behaviors observed in the turbulent vessel are relevant to describe what happens in the engine by studying flame propagation in an optical engine;

- to see if some operating parameters of the engine such as the engine regime have an effect on the response to the flame stretch and if those effects can be linked to the observations made in the turbulent vessel;

- to assess the impact of the various flame stretch responses on the global combustion characteristics especially the combustion phasing which is directly linked to the engine yield;

- to check if the optical engine results can then be extrapolated to other kinds of engines by using an all-metal engine; 
- and finally to determine whether flame stretch sensitivity should be considered as a key factor when developing and classifying a new fuel, and whether it should therefore be integrated in a CFD modeling approach.

\section{Selection of different air-fuel mixtures}

In order to focus on the impact of the different responses of the air/fuel mixtures to flame stretch, several mixtures were selected using the following criterion: mixtures with similar unstretched laminar flame speeds but different flame stretch sensitivities, i.e. different Markstein lengths and Lewis numbers. To measure these properties the classical method of spherical propagation was used. Three different fuels in lean conditions were used: iso-octane, close to gasoline, propane and methane. Lean mixtures of three different hydrocarbons were preferred in order to cover a large range of Lewis numbers [32,33] and because they are more suitable than rich ones for SparkIgnition engine operations.

\subsection{Experimental Set-up}

To select the mixtures by measuring unstretched laminar flame speeds and Markstein lengths, a spherical vessel fully described by Galmiche et al.[34] was used (Figure 1). The combustion chamber is a spherical stainless steel vessel with an inner diameter of $200 \mathrm{~mm}$, equipped with four quartz windows with an inner diameter of $70 \mathrm{~mm}$. Full details of the gas and liquid introduction and ignition procedure can be found in Galmiche et al. [35] and Broustail et al. [36,37]. 6 fans are used for the mixing process and the air/fuel mixture is ignited $5 \mathrm{~s}$ after stopping the fans to avoid any turbulence. Experiments were carried out at 1 bar and $400 \mathrm{~K}$. 

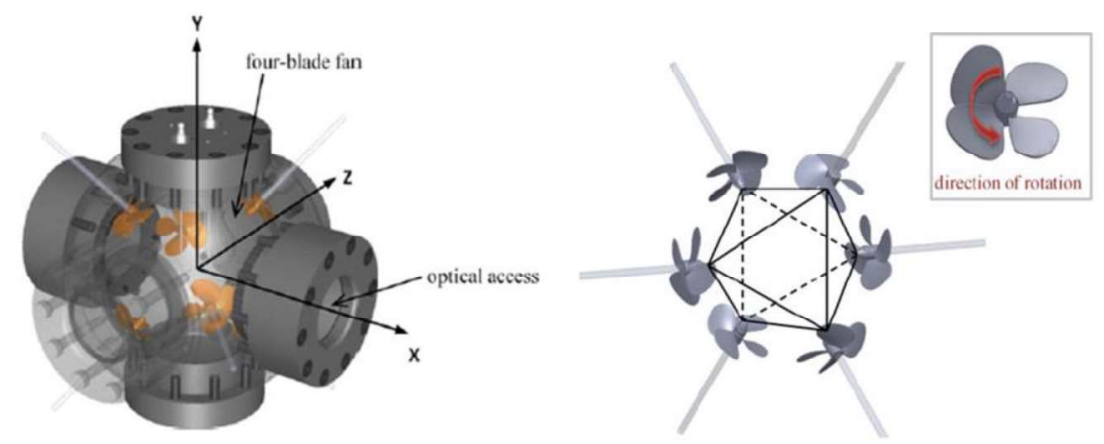

Figure 1. Schematic view of the spherical vessel

The flame speed and Markstein length were measured with Mie-scattering Tomography. The laser sheet was created in the XOY plane (Figure 1) at the center of the chamber using a Nd:YAG Dual Hawk HP laser coupled with a spherical lens (focal length $300 \mathrm{~mm}$ ) and a cylindrical lens (focal length $25 \mathrm{~mm}$ ). The laser sheet was about $0.5 \mathrm{~mm}$ thick and laser pulses were synchronized with a high speed Phantom v1610 camera. The acquisition rate was fixed at 8000 fps with a frame resolution of $768 \times 768$ pixels $^{2}$. The magnification ratio was set at $101.8 \mu \mathrm{m} /$ pixel. Silicon oil droplets were used as seeding and the seeder, a perfume diffuser system, was heated up to $70^{\circ} \mathrm{C}$ in order to decrease the silicon oil viscosity, thus producing smaller and more abundant particles. The temporal flame front radius evolutions were obtained from the image processing. Measurements were limited to flames with a radius greater than $5 \mathrm{~mm}$ and lower than $20 \mathrm{~mm}$ which corresponds to a burnt gas volume that is less than $1 \%$ of the sphere volume. Afterwards only images corresponding to a radius greater than $5 \mathrm{~mm}$ were kept for the processing using the nonlinear model. This makes it possible to overcome the ignition effect. Indeed, in previous work, Bradley et al. $[19,38]$ studied the impact of the ignition energy on the laminar flame speed and Markstein length measurements. They showed that the ignition energy has no impact on the measurement of the laminar flame speed and the Markstein length as long as the post-processing starts with a radius around 5-6 mm. Moreover, since the burnt gas volume does not exceed $1 \%$ of the sphere volume 
the pressure can therefore be considered constant. The laminar flame speed $S_{b}$ was calculated from the derivative of the radius. The nonlinear model proposed by Kelley and Law [16] and the methodology proposed by Halter et al.[18] were then used to obtain the unstretched laminar flame speed $S_{b}{ }^{0}$ and the Markstein length $L_{b}$. An analysis of the different errors linked to the experimental procedure in a previous work [39] showed that the maximum uncertainty in the determination of the laminar flame speed was less than $5 \%$.

\subsection{Selected Mixtures}

Three lean mixtures of methane, propane and iso-octane were selected, as summarized in Table 1. The mixtures present very similar unstretched laminar flame speeds $(2.35 \mathrm{~m} / \mathrm{s} \pm 4 \%)$ and similar thermodynamic properties (adiabatic flame temperature $T_{a d}$, specific heat ratio $c_{p}$, Lower Heating Value $L H V$ ) but very different Markstein lengths and Lewis numbers, leading to different flame stretch sensitivities as expected. $S_{b}{ }^{0}$ and $L_{b}$ are averages of three identical experiments for each mixture while $c_{p}, T_{a d}$ and $L e$ were calculated using a CHEMKIN routine [40] and different kinetic schemes. The Lewis numbers were calculated as the ratio of the thermal diffusivity of the mixture to the mass diffusivity of the deficient species, in this case the fuel. The unstretched laminar burning speed $S_{L}{ }^{0}$ was obtained by multiplying $S_{b}{ }^{0}$ by the expansion ratio $\rho_{b} / \rho_{u}$ calculated with CHEMKIN. Figure 2 shows the laminar propagation speed versus flame stretch measured on the vessel for each fuel during one run. The solid lines represent the nonlinear extrapolation fit presented in equation (3) and they were obtained using the method described by Halter et al. [18] and Tahtouh et al. [39]. It can be seen that the steepness of each curve differs completely whereas the intercept with the yaxis is similar for the three mixtures, which leads to similar unstretched flame speeds and different Markstein lengths. The values obtained for the Markstein lengths and $S_{L}{ }^{0}$ were compared to the literature. For methane at $1 \mathrm{bar}, 400 \mathrm{~K}$ and an equivalence ratio of $0.8, \mathrm{Gu}$ et al. [41] measured a 
$S_{L}{ }^{0}$ of $48.7 \mathrm{~cm} / \mathrm{s}$ and a Markstein length of 0.48 which is a little different from the results in Table 1 but this is mainly due to use of the linear extrapolation technique by Gu et al. which overestimates the unstretched laminar flame speed. For Propane, at 1 bar, $370 \mathrm{~K}$ and an equivalence ratio of 0.8 , Tang et al. [42] measured a $S_{L}^{0}$ of about $47 \mathrm{~cm} / \mathrm{s}$ and a Markstein length of about $1.1 \mathrm{~mm}$ but again with the linear extrapolation technique. Finally for iso-octane, Broustail et al. [36] found a $S_{L}{ }^{0}$ of about $46 \mathrm{~cm} / \mathrm{s}$ and a Markstein length of about $1 \mathrm{~mm}$ at $1 \mathrm{bar}, 423 \mathrm{~K}$ with an equivalence ratio of 0.8 and by using the nonlinear extrapolation technique. The results presented in Table 1 seem then to be in good agreement with the literature.

\begin{tabular}{|c|c|c|c|}
\hline Fuel & Methane [43] & Propane [44] & Iso-octane [45] \\
\hline Equivalence Ratio & 0.85 & 0.72 & 0.8 \\
\hline$S_{b}^{0}(\mathrm{~m} / \mathrm{s})$ & 2.45 & 2.35 & 2.28 \\
\hline$S_{L}^{0}(\mathrm{~cm} / \mathrm{s})$ & 45.8 & 45.6 & 40.6 \\
\hline$L_{b}(\mathrm{~mm})$ & 0.3 & 0.76 & 1.1 \\
\hline$L e$ & 0.99 & 1.88 & 3.05 \\
\hline$T_{a d}(\mathrm{~K})$ & 2130 & 2000 & 2140 \\
\hline$c_{p}\left(\mathrm{~kJ}^{\mathrm{kg}}{ }^{-1} \cdot \mathrm{K}^{-1}\right)$ & 0.79 & 0.79 & 0.80 \\
\hline$L H V\left(\mathrm{~kJ}^{\mathrm{kg}} \mathrm{kg}^{-1}\right)$ & 50000 & 45750 & 44100 \\
\hline
\end{tabular}

Table 1. Properties of the selected mixtures at 1 bar, $400 \mathrm{~K}$. 


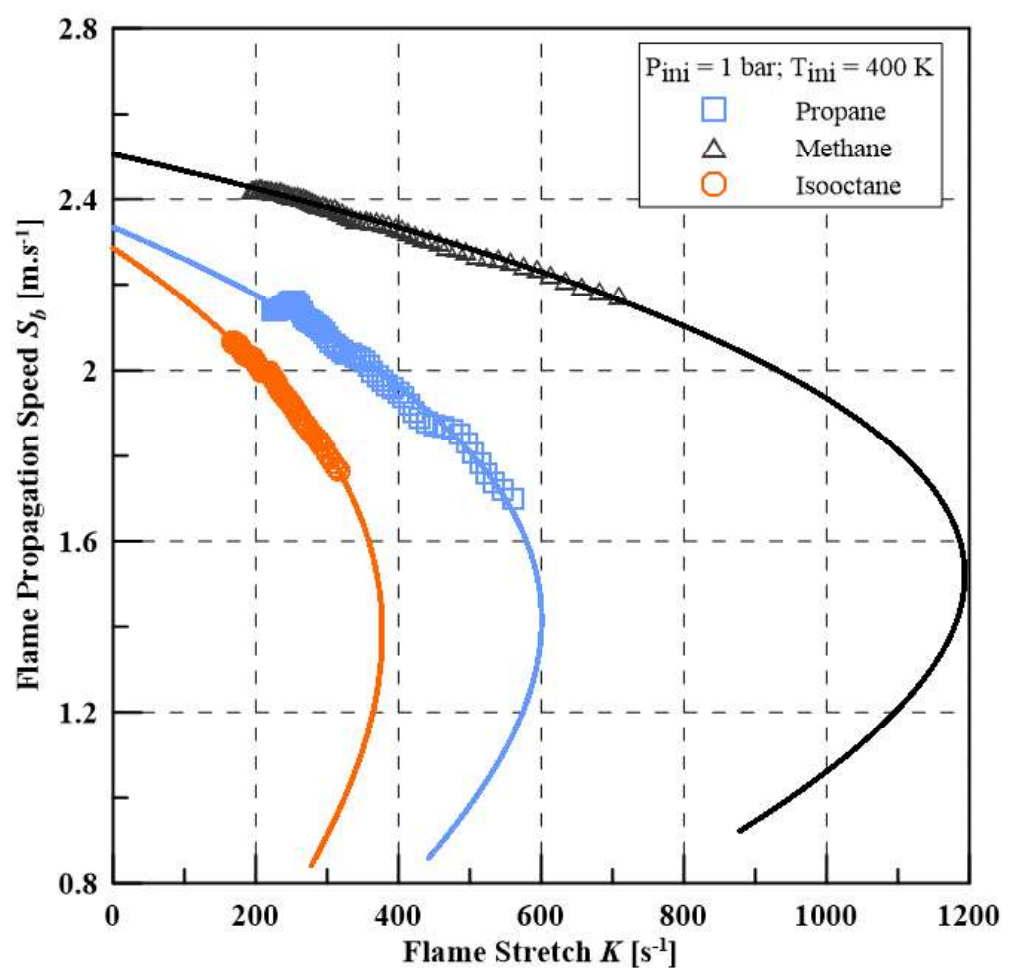

Figure 2. Laminar flame speed versus flame stretch for the three mixtures.

In view of their properties, these mixtures enable the flame stretch response effect to be investigated. The question is then how these mixtures will behave in turbulent conditions. To answer this question, further experiments were carried out in a turbulent spherical vessel in order to investigate flame propagation and structure and the impact of flame stretch sensitivity.

\section{Impact of turbulence on flame propagation for selected mixtures}

\subsection{Experimental Set-up}

In this case, the fans were also used to generate a homogeneous and isotropic turbulence. As shown by Galmiche et al. [34], the six fans of the device generate a homogeneous and isotropic turbulence in a spherical zone of $20 \mathrm{~mm}$ radius around the center of the sphere. Three different fan speeds were used: 5000, 6000 and $7000 \mathrm{rpm}$ corresponding to the following turbulent intensities: 0.86 , 1.04 and $1.21 \mathrm{~m} / \mathrm{s}$ with a constant integral length scale of $3.4 \mathrm{~mm}$. The initial pressure and temperature were kept identical: 1 bar and $400 \mathrm{~K}$ and 10 runs per condition of mixture and turbulent 
intensity were carried out in order to obtain statistical information. The settings for the images and camera were the same as in the laminar regime: the acquisition rate was fixed at $8000 \mathrm{fps}$ with a frame resolution of $768 \times 768$ pixels $^{2}$ and the magnification ratio was set to $101.8 \mu \mathrm{m} / \mathrm{pixel}$. The spatial resolution for the flame contour was estimated at $0.8 \mathrm{~mm}$ by considering a cut-off frequency of 0.16 pixel $^{-1}$ for the contour filtering. Some turbulent properties were deduced from the work of Galmiche et al. [34] and are summarized in Table 2.

\begin{tabular}{|c|c|c|c|c|}
\hline $\begin{array}{c}\text { Fan speed } \\
{[\mathrm{rpm}]}\end{array}$ & $\begin{array}{c}\mathrm{u}^{\prime} \\
{\left[\mathrm{m}^{-1}\right]}\end{array}$ & $\begin{array}{c}\text { Integral length } \\
\text { scale } \\
\mathrm{Lt} \\
{[\mathrm{mm}]}\end{array}$ & $\begin{array}{c}\text { Taylor length scale } \\
\lambda \\
{[\mathrm{mm}]}\end{array}$ & $\begin{array}{c}\text { Kolmogorov length scale: } \\
\eta \\
{[\mu \mathrm{m}]}\end{array}$ \\
\hline 5000 & 0.86 & 3.4 & 1.44 & 134 \\
\hline 6000 & 1.04 & 3.4 & 1.36 & 123 \\
\hline 7000 & 1.21 & 3.4 & 1.28 & 129 \\
\hline
\end{tabular}

Table 2. Turbulent properties at $1 \mathrm{bar}, 400 \mathrm{~K}$ deduced from the work of Galmiche et al. [34]

\subsection{Image processing}

Flame contours, identified as the interface between black and white areas, were obtained from the Mie scattering images after thresholding and binarization. In order to decrease noise and smooth the contour, a low pass filter was applied. Numerous geometrical data can be extracted from the flame contour. Assuming a spherical flame, $R_{s}$ and $R$, the equivalent radii respectively of the burnt gas area and the perimeter were determined as follows:

$$
\begin{aligned}
& R_{s}=\sqrt{\frac{A}{\pi}} \\
& R_{p}=\frac{P}{2 \pi}
\end{aligned}
$$


where $A$ and $P$ are respectively the flame area and perimeter deduced from the tomographic images. The wrinkling ratio $W$ as defined by Renou and Boukhalfa [33] was also calculated:

$$
W=\frac{R_{p}{ }^{2}}{R_{S}{ }^{2}}
$$

A flame propagation speed was then derived from the radius equivalent to the flame area $R_{s}$ :

$$
S_{R S}=\frac{d R_{S}}{d t}
$$

A global flame stretch $K_{\text {global }}$ along the flame surface area $A_{f}$, obtained from the contour evolution was estimated using the classical expression of equation (1). It is clear that the definition used here for the flame stretch is not complete since it does not take into account the velocity gradient parallel to the flame front, i.e. the strain rate. However it is assumed here that the flame stretch is mainly driven by the curvature for different reasons. First, the flame globally keeps a spherical/cylindrical or ellipsoidal shape indicating a strong contribution of curvature to the flame stretch. Secondly, Renou et al. measured the fresh gas flow field using the PIV technique for turbulent premixed expanding flames [46] but with a lower turbulent intensity than for the present study. However they showed that due to the flame expansion the velocity vectors in the fresh gases in the neighborhood of the flame front are normal to this flame front, thus implying a low strain rate. Besides Chaudhuri et al. [47] recently showed with turbulent intensities of 1.29 and $2.57 \mathrm{~m} / \mathrm{s}$ that the geometry of the flame edges remains correlated with the evolution in time and that the stretch due to pure curvature is a more persistent quantity than the tangential strain rate. For those reasons, it can be assumed then that while the definition of the flame stretch given here may not be complete, it nonetheless gives a good overview of the evolution of the true flame stretch as the flame propagates. 
The flame stretch calculated from a $2 \mathrm{D}$ tomography image is underestimated compared to $3 \mathrm{D}$, as the flame growth in the $3^{\text {rd }}$ component is not considered. However as it is a comparative study, we assume that the trends given by the stretch curves will not be changed when considering $3 \mathrm{D}$. Moreover, previous and recent studies [48-50] evaluated how 2D tomographic measurement is relevant compared to 3D by regarding the flame surface density. Consequently, a link between the $2 \mathrm{D}$ stretch estimation and the $3 \mathrm{D}$ flame stretch can be established even if the $2 \mathrm{D}$ measurement underestimates it.

\subsection{Results}

\section{Flame radius and Wrinkling}

The radii obtained from the flame surface for the three fuels and the three fan speeds are presented in Figure 3 with a relative error of $6 \%$, estimated by assuming an overestimation of $+/-0.5$ pixel around the contour location. By considering the standard deviations, uncertainties were estimated by using the method described in [51]. Radii are then given with an uncertainty of $+/-5.5 \%$ and $7.5 \%$, respectively for methane and propane. For isooctane, the uncertainty increases with the fan speed from $+/-7.5 \%$ at $5000 \mathrm{rpm}$ to $+/-18 \%$ at $7000 \mathrm{rpm}$. Methane ignites first and has the fastest developing flame whereas propane and iso-octane burn more slowly. This trend is strengthened when the turbulence intensity is increased. Moreover the scatter from one run to another appears to be different depending on the fuel. The three mixtures can be ranked from the least to the most scattered as follows: methane, propane, and iso-octane. This ranking is the same as the Markstein length ranking. It can be seen that the radius value range of iso-octane at $7000 \mathrm{rpm}$ is lower those of the other mixtures. This can be explained by the fact that the flame is convected and exits the isotropic homogeneous turbulence zone. When this is the case, the data cannot be taken into consideration. 
The evolution of the mean surface radius as a function of the number of samples used was checked for the three mixtures. In the case of propane and methane, statistical convergence was obtained for all turbulent intensities and for iso-octane for the lowest turbulent intensity (5000 rpm). For higher turbulent intensities, due to the response of iso-octane to flame stretch, as the turbulent intensity increases, the flame will experience higher stretch and the variation in the flow field from one run to another has a greater effect. Therefore even with a higher number of samples statistical convergence is not guaranteed for iso-octane. Moreover, for some conditions, the number of samples can be lower than 10 due to convection of the flame kernel either from the gap of the electrodes in the laser sheet plane or outside the laser sheet plane. For example at $7000 \mathrm{rpm}$, only 6 samples were available for isooctane which makes the analysis more precautious in this case. 


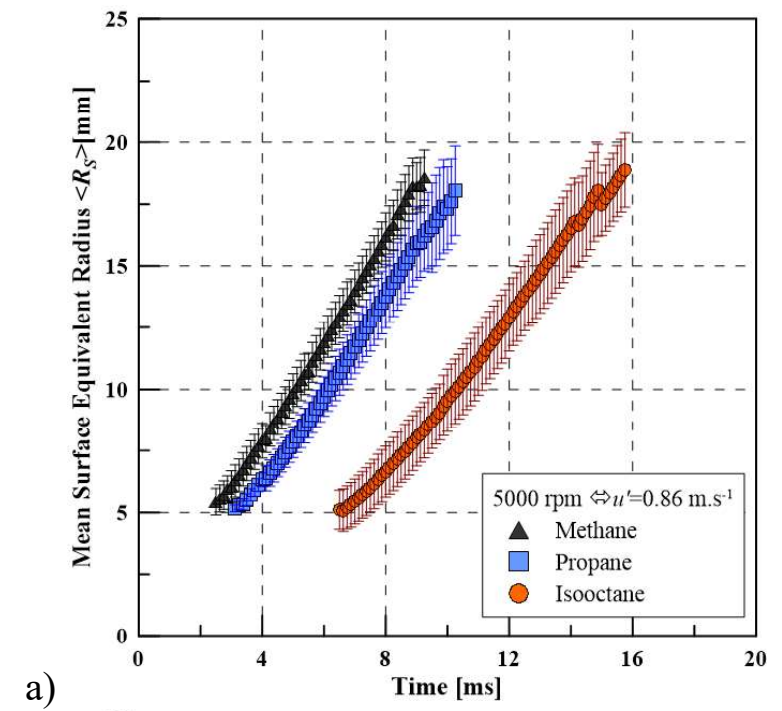

a)

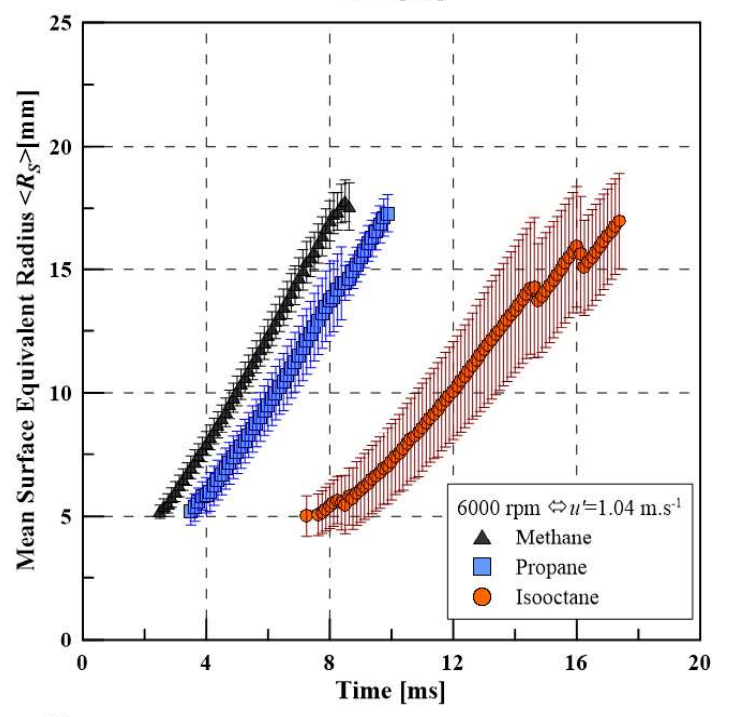

b)

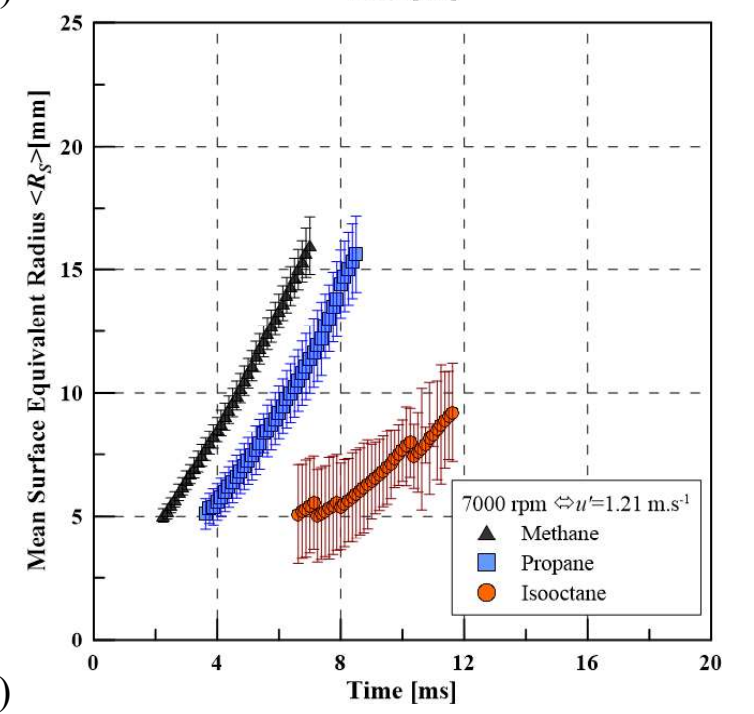

Figure 3. Mean flame radius evolution for the three mixtures: a) 5000, b) 6000 and c) $7000 \mathrm{rpm}$. 
The flame wrinkling ratio defined by equation (7) is plotted versus the flame radius for all mixtures in Figure 4. Results show similar values especially for methane and propane at $5000 \mathrm{rpm}$, thus suggesting flame contours with similar wrinkling. Concerning iso-octane, the strong standard deviation observed makes the analysis harder. When increasing the turbulence intensity, the standard deviation increases especially for propane and iso-octane. The uncertainty on wrinkling in the case of iso-octane is about $+/-44 \%$ in the worst case $(6000 \mathrm{rpm})$ whereas for both methane and propane it remains below $+/-15 \%$ at 5000 and $6000 \mathrm{rpm}$ and below $+/-25 \%$ at $7000 \mathrm{rpm}$. Even if flame wrinkling seems to be constant with the radius for iso-octane, it is difficult to draw any conclusion because of these high uncertainty values. However it can be seen in Figure 4 that flame wrinkling slightly increases with the radius for propane and methane, and its evolution with the radius is less flat when the turbulence intensity increases. Galmiche et al. [34,52] showed that increasing the turbulence intensity results in decreasing the smallest turbulence scales which will then wrinkle the flame even more. Indeed, as shown in Table 2, at 1 bar, $400 \mathrm{~K}$, the Taylor length scale decreases from 1.44 to $1.28 \mathrm{~mm}$ when increasing the fan speed from 5000 to $7000 \mathrm{rpm}$. Meanwhile the length scale that equals the Kolmogorov length scale decreases from 134 to 123 $\mu \mathrm{m}$. 


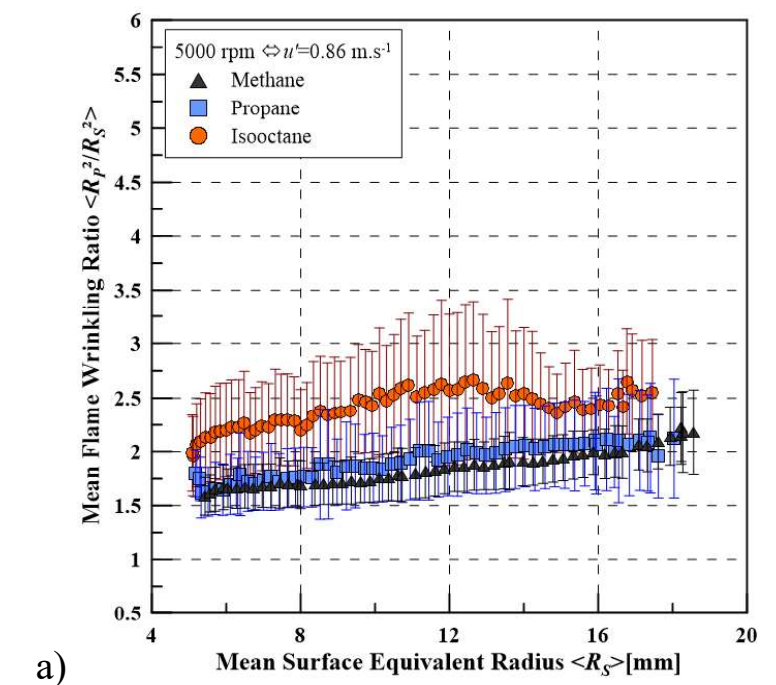

a)

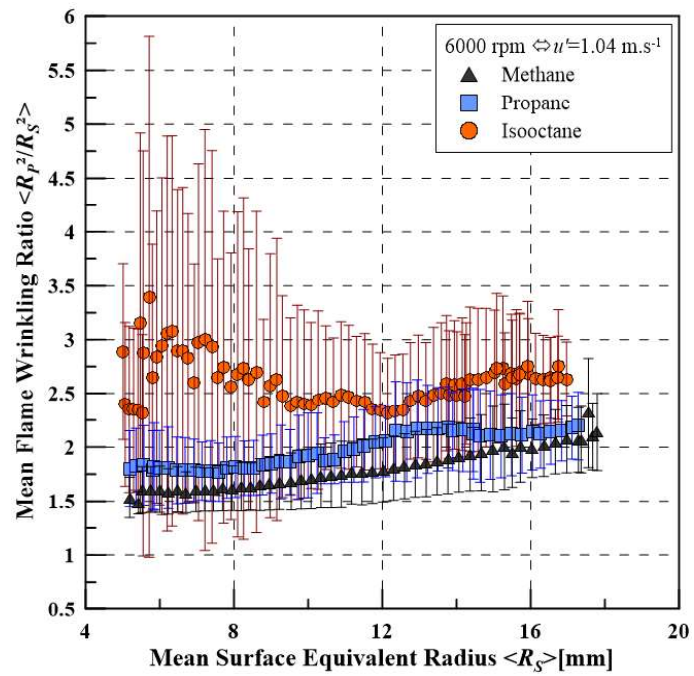

b)

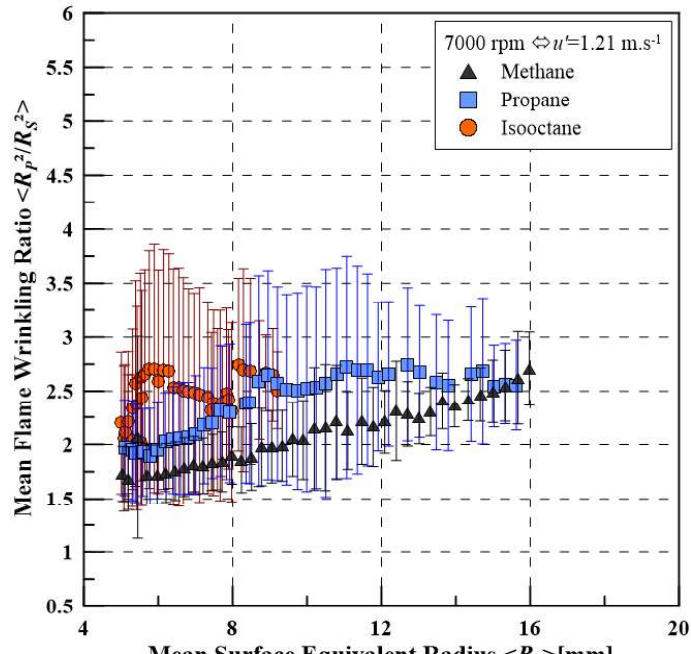

c)

Figure 4. Mean flame wrinkling ratio evolution for the three mixtures: a) 5000, b) 6000 and c) $7000 \mathrm{rpm}$. 
Flame speed and stretch

The flame propagation speeds were calculated as the time derivative of the surface radius. They are plotted versus the flame radius for each turbulence intensity in Figure 5. The mixtures are ranked from the slowest to the fastest as follows: iso-octane, propane, methane, even if the unstretched laminar flame speed is of the same order for all the mixtures. The flame speed increases with the radius for all the mixtures for three reasons. First, the positive value of the Markstein length for the three mixtures implies that the flame speed increases as the flame stretch decreases with propagation. The increasing flame wrinkling shown in Figure 4 may also contribute to increasing the flame speed. Lastly, the interaction between the flame front and the turbulence is not instantaneous. For instance, in case of a turbulence intensity of $1 \mathrm{~m} / \mathrm{s}$ in our device, the turnover timescale for the largest eddies is about $3.4 \mathrm{~ms}$ [34]. Meanwhile the flame can grow by several millimeters and therefore the response time of the flame to the turbulence cannot be neglected compared to the flame propagation time. In other words, flame wrinkling and turbulence are not balanced. As the flame does not reach a steady propagation regime, the flame speed increases continuously. 


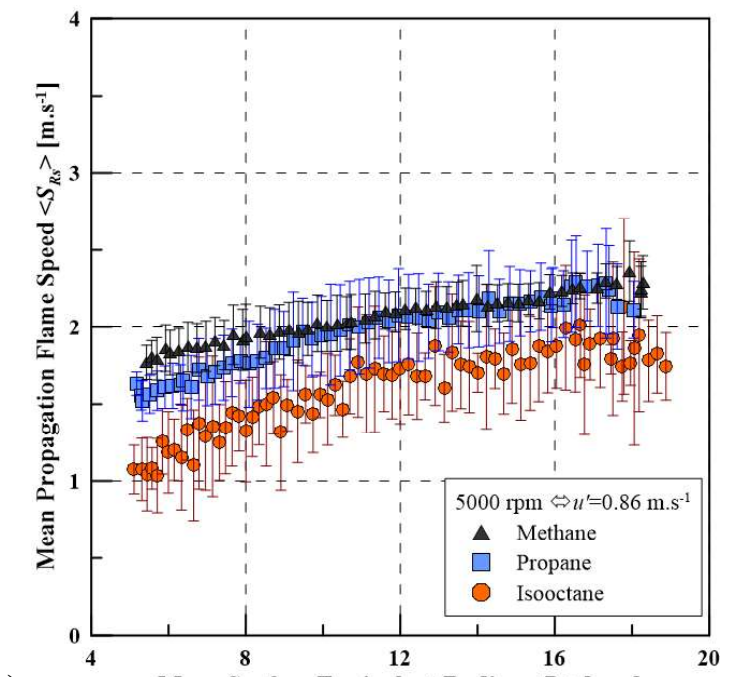

a)

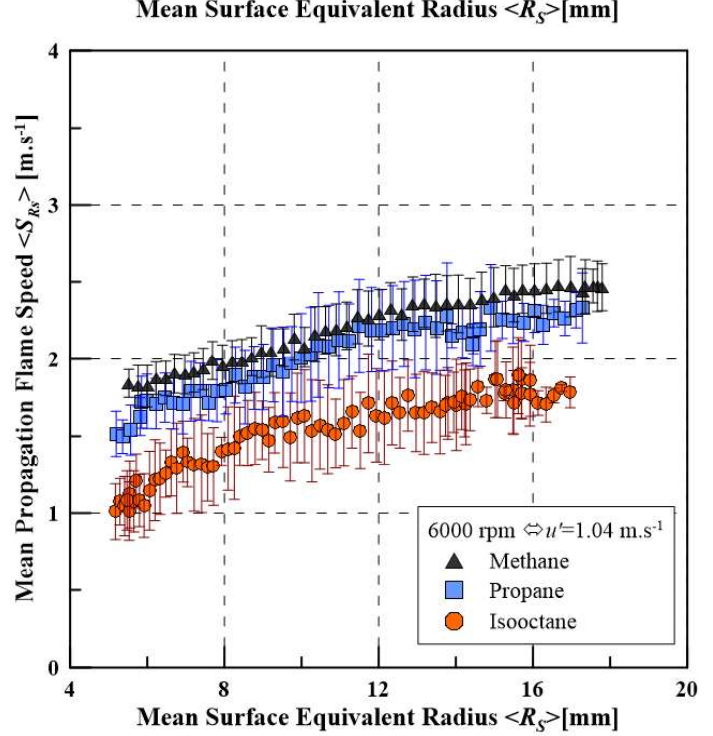

b)

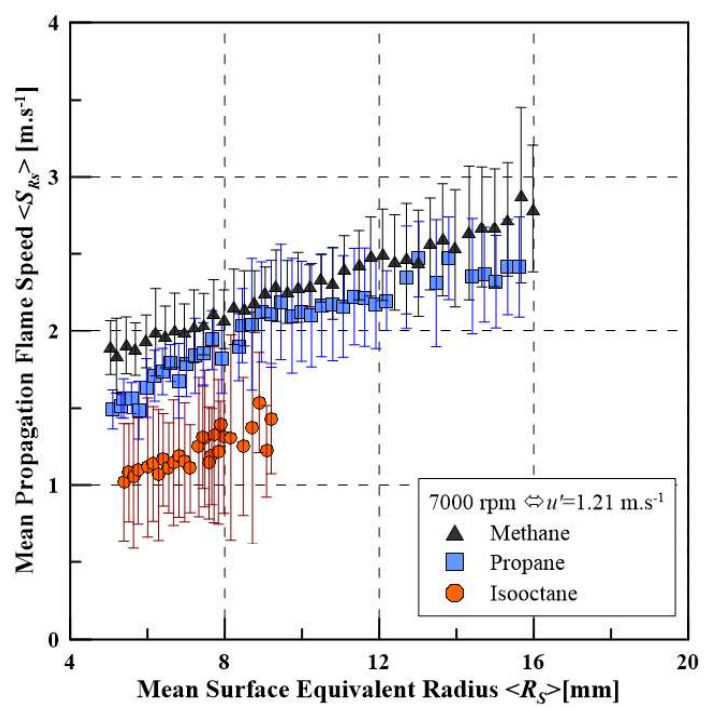

c) Mean Surface Equivalent Radius $<\boldsymbol{R}_{S}>[\mathrm{mm}]$

Figure 5. Mean flame speed evolution for the three mixtures: a) 5000 , b) 6000 and c) $7000 \mathrm{rpm}$. 
The three mixtures react differently to an increase in the turbulence intensity. The radius and flame speed evolutions (Figure 3 and Figure 5 respectively) show that the mean flame speed of methane and propane increases with the turbulence intensity which is consistent with the results of Bradley et al. [23] for lean propane-air at 1 bar, $300 \mathrm{~K}$. As the turbulence intensity increases, the largest eddies become more energetic and Kolmogorov and Taylor length scales become smaller, thus creating higher curvature levels. Flame wrinkling then increases for all the mixtures except iso-octane, as can be seen on Figure 4. This leads to an increase in the flame surface and then to an increase in flame speed for methane and propane. For iso-octane, neither flame speed nor flame wrinkling increase with the turbulence intensity. Lawes et al. [53] measured turbulent burning velocities of an iso-octane-mixture with an equivalence ratio of 0.8 at $1 \mathrm{bar}, 360 \mathrm{~K}$. For u' $=1 \mathrm{~m} / \mathrm{s}$, their results seem to be comparable with those of Figure 5.b). However, it appears that Lawes et al. did not succeed in igniting the mixture for a higher $\mathrm{u}^{\prime}(4 \mathrm{~m} / \mathrm{s})$. This can probably be explained by the fact that the mixture is close to its lean inflammability limit and that the flame faces high stretch levels. Indeed Lawes et al. showed that increasing the turbulence intensity leads to a turbulent burning velocity increase for a stoichiometric iso-octane-air mixture. This behavior is not seen for the lean mixture of iso-octane in Figure 5. With its high Lewis number, the lean iso-octaneair mixture is more resistant than methane to flame wrinkling and moreover the high stretch levels can be responsible for quenching at some point. As a result, there is competition between the positive effect of turbulence in speeding up the flame and the negative effect of both the Lewis number on flame wrinkling and the lean inflammability limit. Also, the low number of samples for iso-octane at $7000 \mathrm{rpm}$ makes the analysis more precautious from a statistical point of view.

The global flame stretch evolution is presented versus the flame radius in Figure 6. As expected the flame stretch decreases as the flame grows. Some differences in flame stretch levels can be 
observed between the different mixtures. This is probably due to the difference in the flame propagation speed which is used to calculate flame stretch in equation (1). It can also be seen that the increase in turbulence intensity increases flame stretch, particularly for small flame radii. 


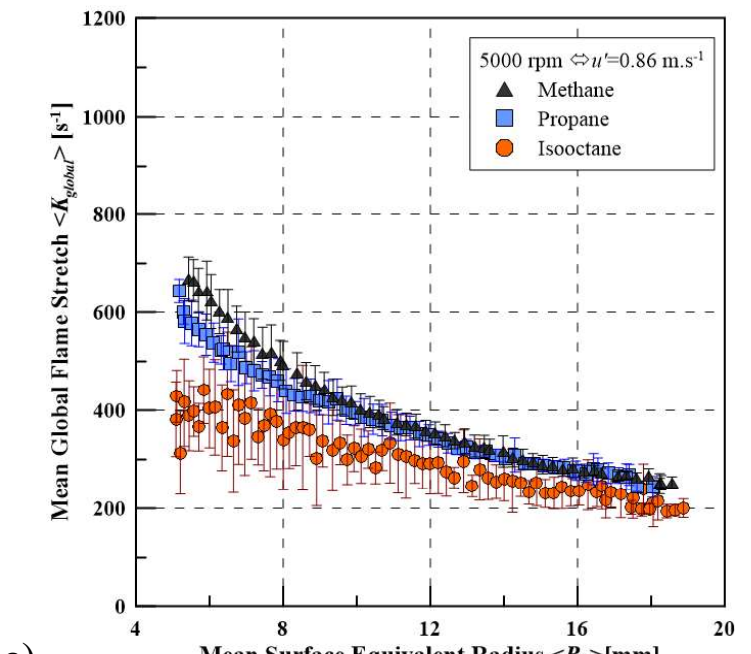

a)

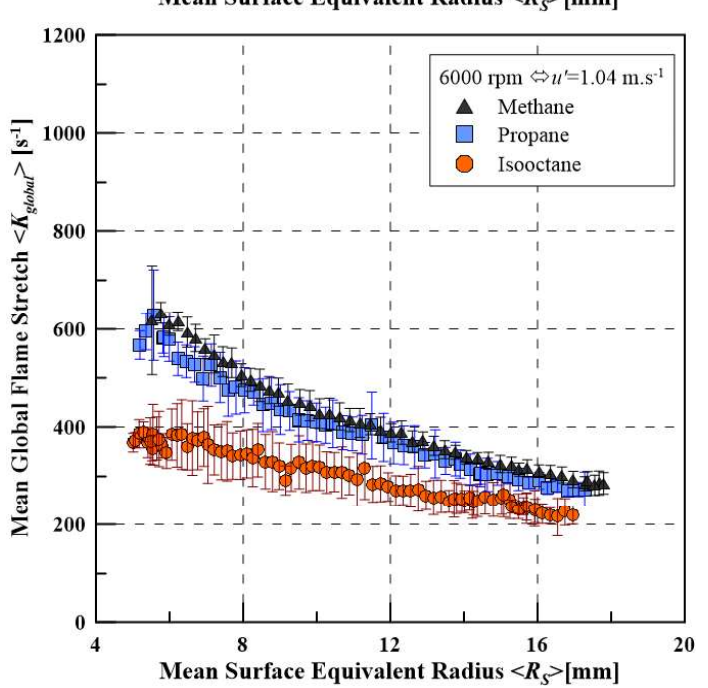

b)

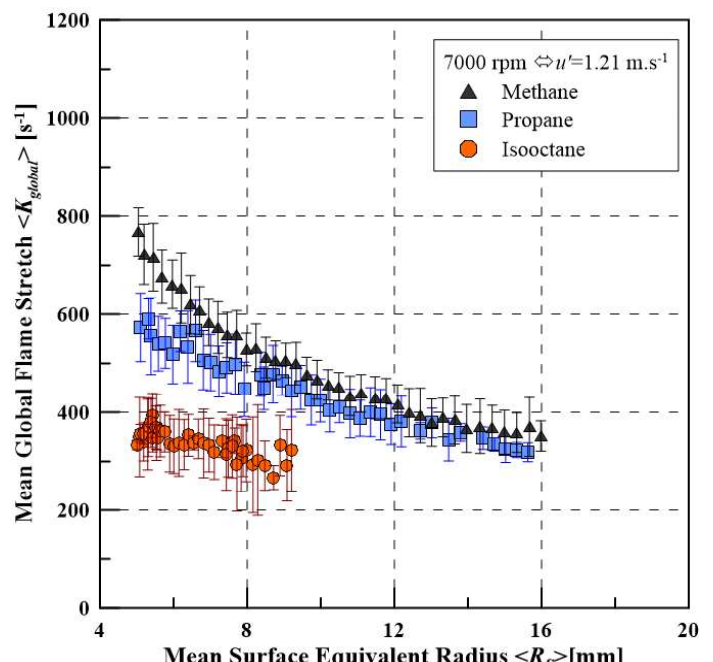

c)

Figure 6. Mean Global flame stretch evolution for the three mixtures: a) $5000 \mathrm{rpm}$, b) $6000 \mathrm{rpm}$, c) $7000 \mathrm{rpm}$. 
Flame stretch sensitivity

As in laminar combustion measurements, the flame propagation speed is plotted as a function of the global flame stretch in Figure 7 in order to compare the flame stretch sensitivities. The averaged plots can then be linearly extrapolated to obtain a non-stretched flame speed as well as an "arbitrary" stretch sensitivity corresponding to the slope of the extrapolation line.

The slope values deduced from Figure 7 are presented in Table 3 . While the mixtures have the same stretch sensitivity ranking as the one observed in Table 1, the stretch sensitivities are higher than the Markstein lengths measured in laminar combustion. This can be explained by the fact that the flame speed increase due to flame wrinkling is added to the flame speed increase due to the decrease in flame stretch. This is clearly visible on the methane mixture since its flame stretch sensitivity increases with the turbulent intensity, as does the flame wrinkling acceleration. It can also be seen that the flame stretch sensitivities are constant from $\mathrm{u}^{\prime}=0.86$ to $1.04 \mathrm{~m} / \mathrm{s}$. This may be due to flame wrinkling that remains unmodified by turbulence. The flame stretch sensitivity obtained at $7000 \mathrm{rpm}$ for propane and iso-octane should be considered with caution due to the strong deviation in this configuration. 


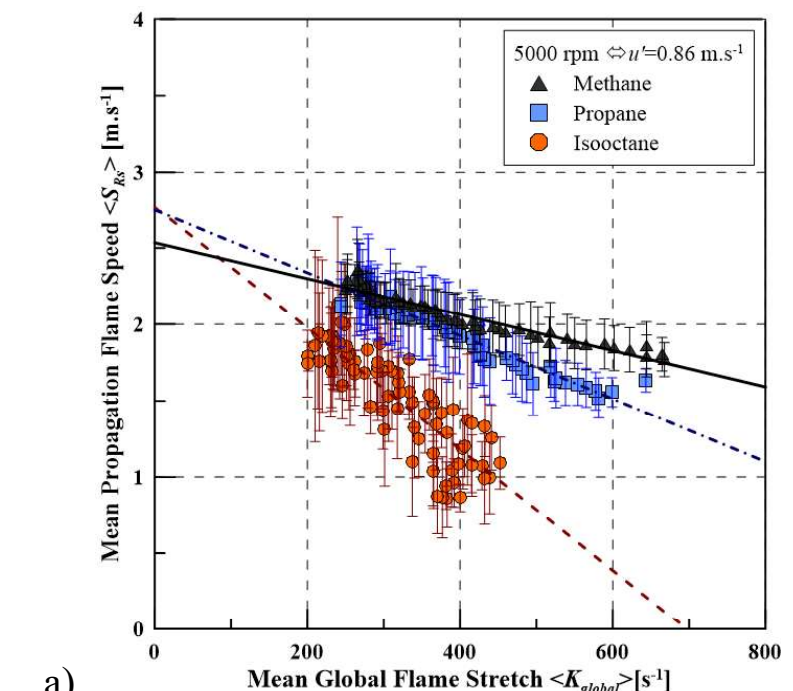

a)

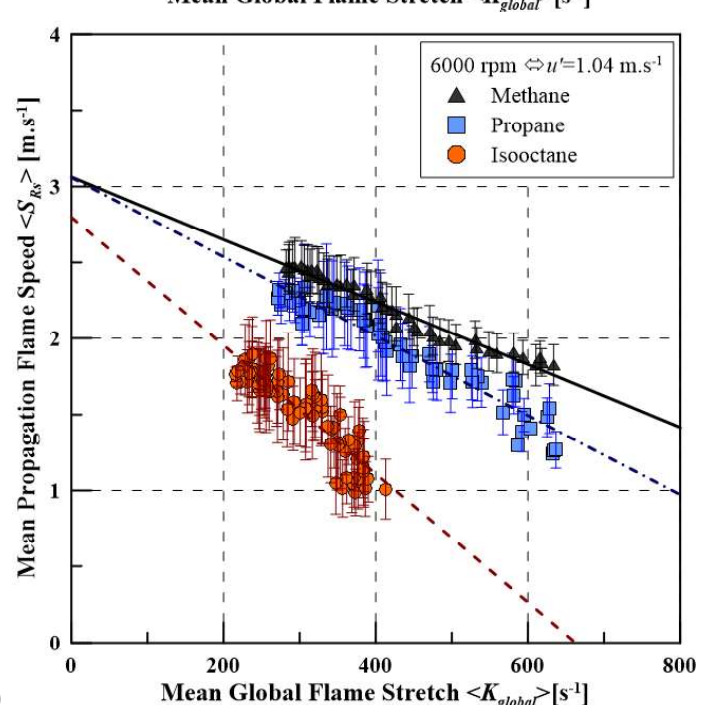

b)

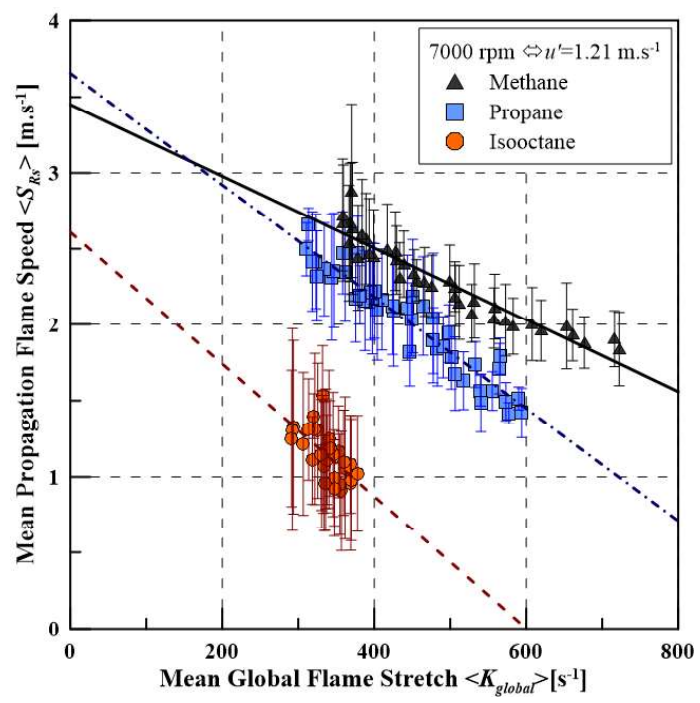

Figure 7. Mean flame speed versus mean flame stretch for the three mixtures: a) $5000 \mathrm{rpm}, \mathrm{b}$ ) $6000 \mathrm{rpm}, \mathrm{c}) 7000 \mathrm{rpm}$. 


\begin{tabular}{|c|c|c|c|}
\hline Fuel & Methane & Propane & Iso-octane \\
\hline$u^{\prime}=0.86 \mathrm{~m} \cdot \mathrm{s}^{-1}$ & 0.9 & 2.4 & 5.5 \\
\hline$u^{\prime}=1.04 \mathrm{~m} \cdot \mathrm{s}^{-1}$ & 1.9 & 2.7 & 5.7 \\
\hline$u^{\prime}=1.21 \mathrm{~m} . \mathrm{s}^{-1}$ & 2.1 & 5.0 & 8.1 \\
\hline
\end{tabular}

Table 3. Arbitrary Flame stretch sensitivities [mm] deduced from the extrapolation fits of Figure 7.

The differences observed in terms of flame speed response to stretch in the laminar regime are therefore also visible in turbulent conditions. These differences may also be visible in a SparkIgnition engine and may impact engine performance. To check this, experiments in optical and allmetal engines were carried out.

\section{Combustion Behavior in an Optical Spark-Ignition Engine}

The objective here is to verify if the different behaviors observed in the turbulent vessel are also reproduced with an engine despite the high pressure and temperature conditions in the cylinder and the convective velocity.

\subsection{Experimental Set-up}

The experiments were performed in an optical 0.5 L 4-valve pent-roof chamber single-cylinder engine (Figure 8). Engine specifications are given in Table 4. Optical access was provided by two lateral fused silica windows and a fused silica window set up at the top of an elongated piston. An optical encoder mounted on the crankshaft provides a 0.1 Crank Angle Degree (CAD) resolution for pressure acquisition. The intake pressure was fixed to 0.7 Bar. In order to avoid pressure oscillations, the air passed through a plenum before the intake pipe. The intake air was heated to 
allow the evaporation of liquid fuels and the fuels were injected inside the intake pipe to have an homogeneous mixture. In the case of gaseous fuels, a gas diffuser was used. In the case of liquid fuels, a single-hole swirling injector was used and 4 injections per cycle were done to ensure a good premixed mixture in the intake pipe. The fuel air mixture was ignited every 6 cycles thus implying no burnt gas residuals.

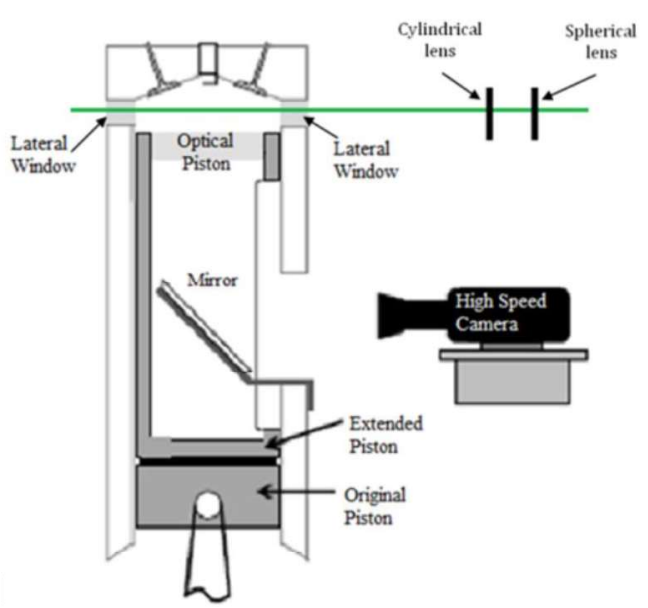

Figure 8. Schematic view of the optical engine for laser tomography imaging configuration. 


\begin{tabular}{|l|l|l|}
\hline Engine & $\begin{array}{l}\text { J4S Renault, } \\
\text { optical engine }\end{array}$ & $\begin{array}{l}\text { EP6, PSA } \\
\text { all-metal engine } \\
\text { (see part 4) }\end{array}$ \\
\hline Displaced Volume & $0.5 \mathrm{~L}$ & $0.4 \mathrm{~L}$ \\
\hline Valves & 4 & 4 \\
\hline Compression ratio & 9.5 & 10.5 \\
\hline Stroke & $82 \mathrm{~mm}$ & $85.8 \mathrm{~mm}$ \\
\hline Bore & $88 \mathrm{~mm}$ & $77 \mathrm{~mm}$ \\
\hline Connecting Rod & $127 \mathrm{~mm}$ & $138.5 \mathrm{~mm}$ \\
\hline Intake Pressure & $0.7 \mathrm{bar}$ & $0.7 \mathrm{bar}$ \\
\hline Intake Temperature & $100{ }^{\circ} \mathrm{C}$ & $127^{\circ} \mathrm{C}$ \\
\hline Ignition Timing & $30 \mathrm{CAD}$ BTDC & $30 \mathrm{CAD} \mathrm{BTDC}$ \\
\hline Firing Frequency & $1 / 6 \mathrm{cycles}$ & Every cycle \\
\hline Tumble Ratio & $\sim 1[54]$ & $\sim 2.4[55]$ \\
\hline
\end{tabular}

Table 4. Specifications of the optical and all metallic engines

In the literature, two different studies were performed on the optical engine:

- First, [27] focused on the flame structure using Mie-Scattering tomography with the engine running at $1200 \mathrm{rpm}$. The estimated turbulence intensity was about $0.95 \mathrm{~m} / \mathrm{s}$ with a maximum mean velocity of $2.5 \mathrm{~m} / \mathrm{s}$ at $1200 \mathrm{rpm}$ and 1 Bar intake pressure at 14.4 CAD BTDC [41]. The frame resolution was $512 \times 512$ pixels $^{2}$ with a magnification ratio similar to that of the vessel experiments: $0.111 \mathrm{~mm} /$ pixel. 50 consecutive firing cycles were acquired for the analysis. 
- Second, [26] focused on the engine speed effect on flame propagation using direct visualization of the flame with the engine running at 1400, 1600, 1800 and $2000 \mathrm{rpm}$. The frame resolution was $256 \times 256$ pixels $^{2}$ with a magnification ratio of $0.196 \mathrm{~mm} / \mathrm{pixel} .100$ consecutive firing cycles were acquired for each engine speed.

The change in the optical technique is mainly due to the laser pulse frequency limitation. Indeed the laser used for tomography has a fixed frequency: $12.5 \mathrm{kHz}$. This frequency corresponds to one image taken every 0.6 crank angle at $1200 \mathrm{rpm}$. To maintain the same crank angle resolution for the images at $2000 \mathrm{rpm}$, a $20 \mathrm{kHz}$ frequency is needed. Direct visualization was therefore chosen to study the engine regime effect.

Obviously using direct visualization does not make it possible to calculate the flame wrinkling and to analyze the flame structure. Yet, the flame growth can still be investigated. Besides in a previous study [26], it was shown, using two planes of visualization, that the flame mainly propagates in the horizontal direction especially after reaching the piston. Moreover, the work of Tahtouh et al. $[56,57]$ in the same optical engine showed that both direct visualization and tomography give the same trends regarding flame growth. Therefore, comparing the flame growth behavior for different air-fuel mixtures seems to be possible even if the two techniques will not give the same absolute values.

Further details about the experimental configuration and optical diagnostics can be found in [26] and [27]. 


\subsection{Flame propagation}

Using the same technique and methodology as in the experiments in the spherical vessel, the parameters deduced from the radius evolution described in equations (1), (5) and (6) were also estimated, and averaged on 50 cycles. The local flame curvature was also studied as described in [27]. The mean surface equivalent flame radius $R_{s}$ evolution is plotted for all mixtures in Figure 9 with a relative error of $6 \%$. Standard deviation bars are also displayed on the plot representing the cycle-to-cycle variability. They are quite similar for all the fuels, leading to a similar uncertainty of about $+/-7 \%$. The radius values of the propane and iso-octane mixtures are similar, particularly at the end of the acquisition. Methane has higher radius values than propane and iso-octane for the same CAD. The trends seem to be in good agreement with those obtained in the turbulent vessel (Figure 3) and with the work of Aleiferis et al. in [25] at $1500 \mathrm{rpm}$ even if the standard deviation in Figure 9 is up to $20 \%$. It can also be seen that the mixtures can be ranked according to the slope of the radius evolution, i.e. flame speed, as follows: iso-octane, propane, methane. Flame development for iso-octane and propane is delayed compared to methane. 


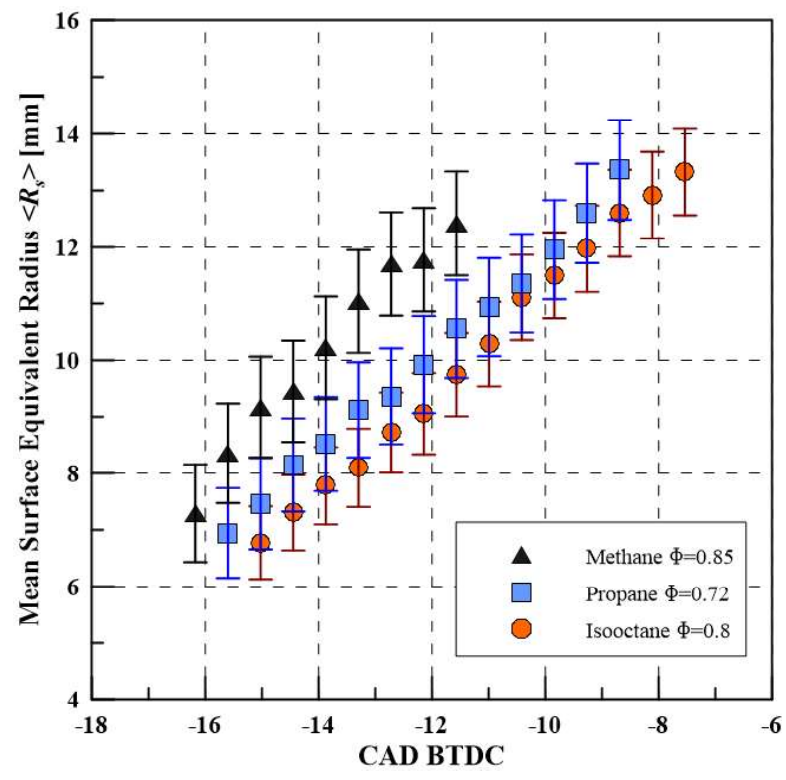

Figure 9. Flame radius evolution versus Crank Angle Degree for the three mixtures [27].

Before analyzing the flame images in greater detail, it was first checked that the mixture selection criterion was still valid in the engine conditions, i.e. at high pressure and temperature. The Lewis number and unstretched laminar burning speed were therefore estimated from CHEMKIN routines using the following kinetic schemes: GRI-Mech 3.0 for methane [43], USC Mech II for propane [44] and Hasse et al. [45] for iso-octane. In-cylinder pressure and temperature were used as input for the CHEMKIN simulation. The in-cylinder temperature was obtained by using a classical thermodynamic analysis based on the cylinder pressure evolution without considering a two-zone model. However this temperature corresponds to a mean "thermodynamic" temperature inside the cylinder and overestimates the fresh gas temperature. The burning speed will therefore be overestimated as well. But for small flame radii (below $10 \mathrm{~mm}$ ), the part of burnt gases can be neglected and the laminar burning speed will not be so overestimated.

As shown in [27] with the CHEMKIN calculations, the Lewis numbers remain quite constant at different values for each mixture during flame propagation while the unstretched laminar burning 
speed is similar for all the mixtures during the onset of combustion. The selected mixtures thus enable the impact of flame stretch sensitivity on flame development in the engine to be studied.

\section{Flame structure: Wrinkling}

Since the selected mixtures have different Lewis numbers, their flame wrinkling should be different. Figure 10 shows the evolution of the wrinkling ratio versus the surface equivalent flame radius $R_{S}$. It can be seen that flame wrinkling increases for all the mixtures. Moreover iso-octane, which has the highest Lewis number, has the lowest wrinkling ratio. This indicates that the most stretch-sensitive mixture has the least wrinkled flame front. Indeed, a high Lewis number tends to decrease thermo-diffusive instabilities, leading to a stabilizing effect on the flame front and thus decreasing wrinkling as well as flame speed. Similar behavior was observed by Renou et al. [33] with methane, propane, and hydrogen as fuels. The figure shows that the wrinkling ratio versus $R_{S}$ increases only slightly for methane and propane whereas the increase for iso-octane is more pronounced. Pajot [58] measured similar levels of flame wrinkling ratios for lean propane-air mixtures $(\phi=0.9)$ in the same engine, and found a value of 8 for a radius of $7.5 \mathrm{~mm}$. Since methane and propane wrinkling increases only slightly, they appear to have almost reached their steadystate propagation regime. 


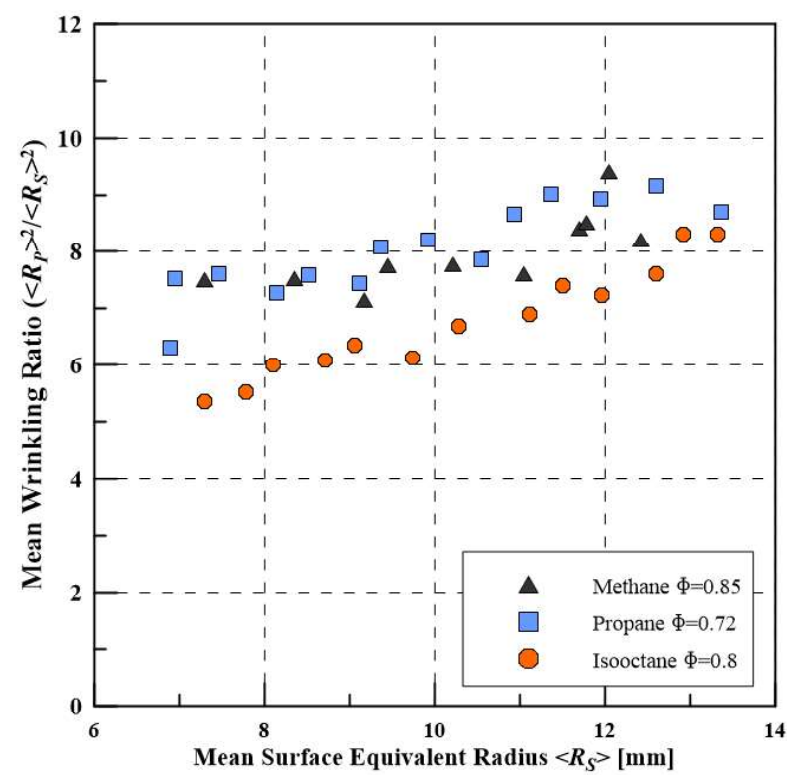

Figure 10. Mean Flame wrinkling evolution versus mean flame radius for the three mixtures [27].

As the wrinkling of iso-octane increases strongly, it takes longer to reach its steady-state propagation regime. A high Lewis number may therefore be responsible for delaying the stabilization of flame propagation. Unlike in the turbulent vessel, the ranking observed in flame wrinkling values seems to be consistent with the Lewis number of the mixtures. Nevertheless, considering the standard deviations observed on $R_{P}$ (up to $25 \%$ ) in the engine and on flame wrinkling in the vessel, it is difficult to conclude on that point. Concerning the flame curvature, no difference in the averages or in the standard deviation was observed [27], thus suggesting a similar flame structure statistically.

Flame stretch sensitivity

As previously done in laminar and turbulent combustion in the spherical vessel, the equivalent flame speed is plotted versus the flame stretch in Figure 11. For all mixtures, flame speed can be linked to flame stretch using a linear model such as Clavin's model [15]. The flame stretch 
sensitivity of each mixture can then be measured as the slope of each curve. The mixtures are ranked from the most to the least stretch-sensitive as follows: iso-octane $(1.7 \mathrm{~mm})$, propane $(0.74$ $\mathrm{mm})$, methane $(0.55 \mathrm{~mm})$, which corresponds to the inverse ranking of the Lewis number. The tendencies are therefore in good agreement with turbulent combustion measurements in the vessel (Figure 7) but also with Markstein lengths in the laminar combustion regime.

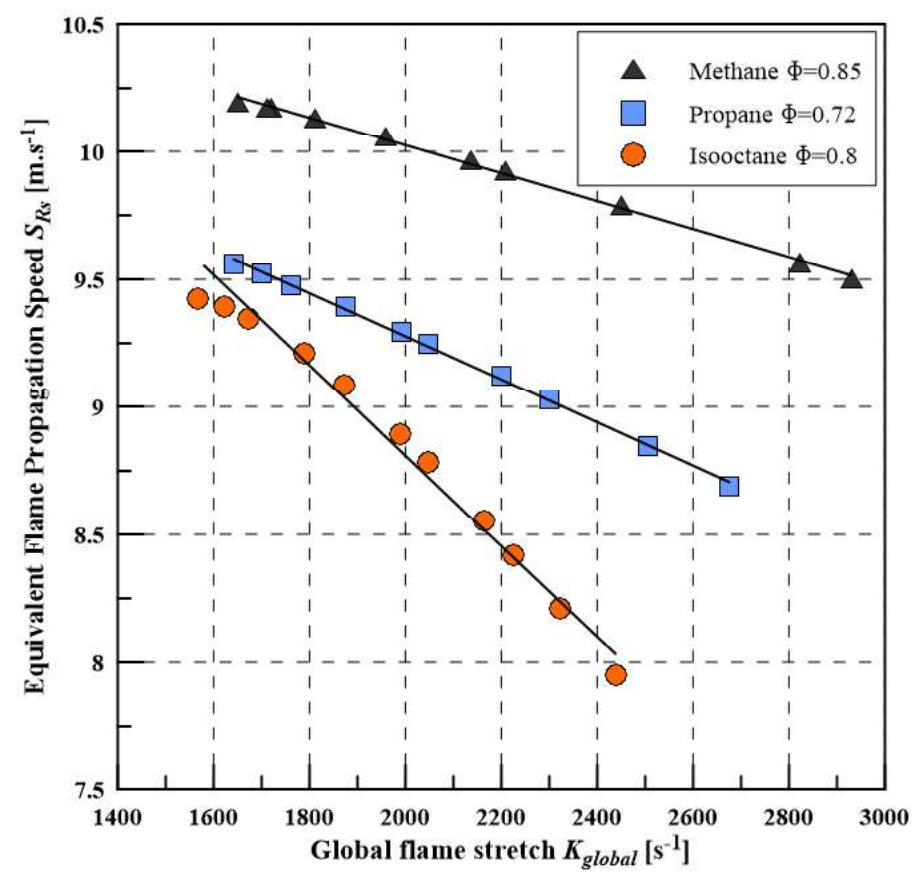

Figure 11. Mean flame speed versus mean flame stretch for the three mixtures at $1200 \mathrm{rpm}$.

\section{Laminar/Turbulent/Engine Comparison}

To compare the results obtained in laminar and turbulent conditions and in the optical engine, a dimensionless flame speed, defined as the time derivative of the radius divided by its value at zero stretch is plotted versus a dimensionless flame stretch, $K . \delta_{L}^{0} / S_{L}^{0}$ (Fig. 12). First, from laminar to turbulent conditions, the slopes of the curves increase due to the increase in flame wrinkling with turbulence. Second, from turbulent conditions to engine data, the slopes of the curves decrease. This can be explained by the lower Markstein lengths in engine conditions because of 
the higher pressure and temperature. Whatever the experimental set-up and the conditions, the flame stretch sensitivity ranking remains the same, as can be seen from the values of dimensionless flame stretch sensitivities in Table 5. The stretch sensitivities are defined here as the slopes displayed by the linear extrapolation of the curves in Figure 12. Consequently, the measurement of Markstein lengths in laminar combustion is a key parameter to compare turbulent and engine combustion behavior for different fuels.

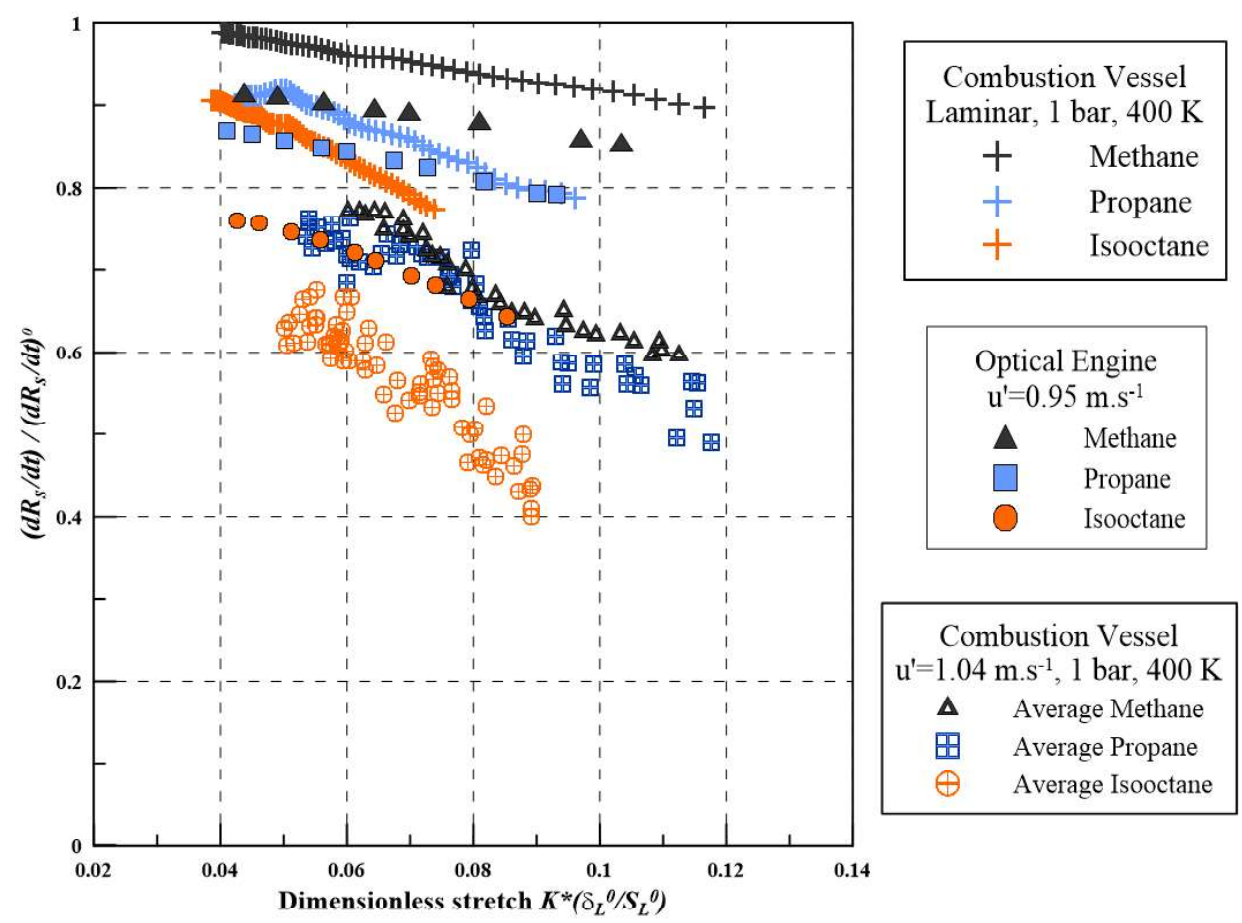

Figure 12. Dimensionless speed versus dimensionless stretch for the three experimental setups

\begin{tabular}{|c|c|c|c|}
\hline Fuel & Methane & Propane & Iso-octane \\
\hline Vessel (Laminar, 1bar, 400 K) & 1.2 & 2.7 & 3.8 \\
\hline Vessel (Turbulent, u'=1.04 m/s, 1 bar, 400K) & 3.8 & 4.6 & 6.2 \\
\hline Optical Engine (u'=0.95 m/s, 6.1 bar and 565 K at IT) & 1.1 & 1.8 & 2.7 \\
\hline
\end{tabular}

Table 5. Dimensionless flame stretch sensitivities for three experimental set-ups. 


\subsection{Effect of engine speed}

The effect of engine speed on the flame propagation was investigated with the same engine as that used in [26] by direct visualization of the flame. The engine speeds studied were 1400, 1600, 1800 and $2000 \mathrm{rpm}$. As can be seen from the Heywood equation [59] (equation 9), increasing the engine speed and therefore the piston speed increases the turbulence intensity:

$$
u^{\prime}=C * \overline{S_{p}}
$$

with $u^{\prime}$ the turbulence intensity, $C$ a constant value and $\overline{S_{p}}$ the piston speed.

A lean butanol-air mixture was added to have a fuel with a Lewis number between that of propane and iso-octane. The equivalence ratio for the air-propane mixture was modified slightly in order to fit the properties of the butanol mixture better. The properties of the different mixtures at ignition timing conditions ( 6 bar, $600 \mathrm{~K}$ ) are summarized in Table 6 . The selection criterion, i.e. the same unstretched speed but a different stretch sensitivity, is still valid at least for methane and iso-octane, and propane and butanol. 


\begin{tabular}{|c|c|c|c|c|}
\hline Fuel & $\begin{array}{c}\text { Methane } \\
\text { GRI-Mech [43] }\end{array}$ & $\begin{array}{c}\text { Propane } \\
\text { USC-Mech II } \\
{[44]}\end{array}$ & $\begin{array}{c}\text { Butanol } \\
\text { Sarathy et al. [60] }\end{array}$ & $\begin{array}{c}\text { Iso-octane } \\
\text { Hasse et al.[45] }\end{array}$ \\
\hline ER & 0.85 & 0.8 & 0.75 & 0.80 \\
\hline$S_{L}^{0}(\mathrm{~cm} / \mathrm{s})$ & 56.40 & 66.93 & 69.40 & 56.70 \\
\hline Lewis & 0.99 & 1.76 & 2.12 & 2.85 \\
\hline$T_{\text {adiab }}(\mathrm{K})$ & 2277 & 2255 & 2190 & 2275 \\
\hline$c_{p}\left(\mathrm{~kJ} \cdot \mathrm{kg}^{-1} \cdot \mathrm{K}^{-1}\right)$ & 0.86 & 0.86 & 0.87 & 0.87 \\
\hline$L H V\left(\mathrm{~kJ}^{2} \mathrm{~kg}^{-1}\right)$ & 50000 & 45750 & 33075 & 44100 \\
\hline Lean operating & 0.7 at $10 \mathrm{~atm}, 298 \mathrm{~K}$ & 0.7 at 5 bar, & 0.7 at 5 bar, & 0.8 at 5 bar, \\
\hline $\operatorname{limit}(E R)$ & [61] & $298 \mathrm{~K}[62]$ & $423 \mathrm{~K}[36]$ & $423 \mathrm{~K}$ [36] \\
\hline
\end{tabular}

Table 6. Properties of the selected mixtures at 6 bar, $600 \mathrm{~K}$ calculated with different kinetic schemes in CHEMKIN.

\section{Flame radius evolution}

The effect of engine speed on flame radius evolution is presented for all mixtures at $1400 \mathrm{rpm}$ and $2000 \mathrm{rpm}$ in Figures 13 a) and b) respectively and for each mixture at all the engine speeds in Figures 14 (a), (b), (c), (d). Due to the sufficient number of cycles acquired here, uncertainty is quite low and remains at $+/-5 \%$ for all fuels and conditions.

The evolution of the flame radius obtained with direct visualization is in good agreement with the results from tomographic experiments (parts 2 and 3) and with the work of Aleiferis et al. [25]. All the mixtures have similar radius evolutions except for iso-octane which ignites later and burns more slowly. At $2000 \mathrm{rpm}$, butanol combustion also begins to be delayed compared to that of 
methane and propane. Figure 14 shows that the increase in the engine speed, i.e. the turbulent intensity, increases the flame speed more in the case of methane than iso-octane. While the flame speed increase with turbulence intensity was already observed in Figure 6 for methane, no trend can be extracted for iso-octane which even appears to slow down, judging from its radius evolution with turbulence intensity in Figure 3. In Figure 14, the engine speed increase and therefore the turbulence increase appears to be responsible for a small increase in the flame speed even for the iso-octane mixture. It is important to recall here that the high pressure in the engine may have an effect on flame wrinkling, thus explaining the different effect of turbulence intensity on the radius evolution between the vessel and the engine for iso-octane. For methane, the strong flame speed increase can be explained by a positive effect of turbulence on flame wrinkling and the fact that the mixture is not really affected by stretch. To be more precise, in the vessel, when increasing the turbulence intensity the flame speed for iso-octane is not increased because of the flame stretch that prevents the flame from expanding in the beginning. In the engine, the flame speed of the isooctane flame seems to increase when increasing the engine regime. This can be due to the high pressure of the engine that helps the flame to wrinkle and to high temperature that speeds up the propagation, thus compensating the stretch effect. The increase in turbulent flame speed when increasing the pressure has been indeed already shown by Lawes et al. [53]. For the other fuels, since they are less sensitive to stretch, the positive effect of the turbulence increase seen in the vessel is combined with the high pressure and temperature that help the flame to wrinkle and speed up. Therefore these two effects are responsible for a stronger flame speed increase for methane than for iso-octane. To sum up, even if the stretch increases with engine speed [26], it has no effect on the flame propagation itself for the methane-air mixture. On the contrary, the iso-octane mixture is much more sensitive to stretch and its high Lewis number makes it resistant to wrinkling, thus explaining the low speed increase with engine speed for this mixture. A similar observation and 
comparison can be made for butanol and propane even if it is less noticeable in Figure 14. The increase in engine speed is responsible for a higher increase in the flame speed for propane than for butanol.

a)

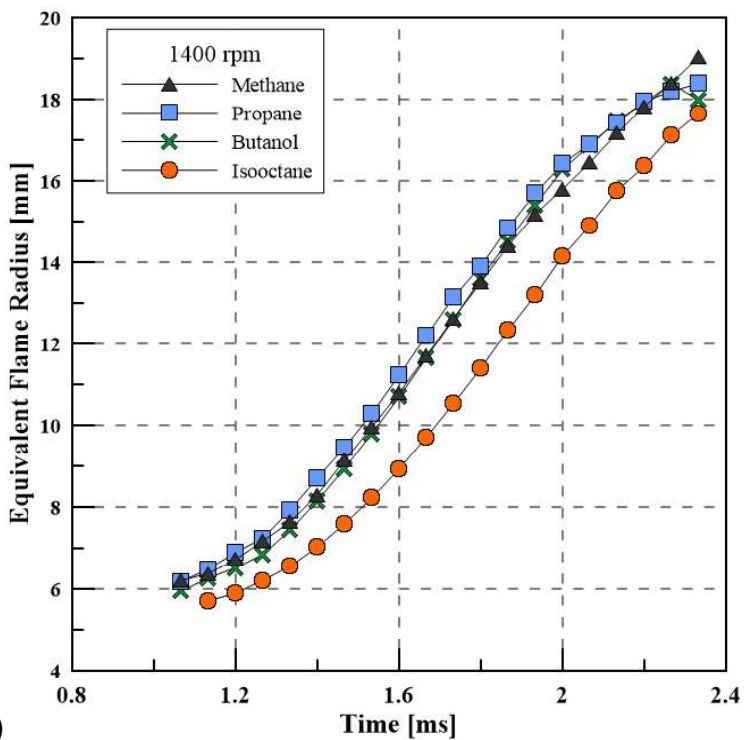

b)

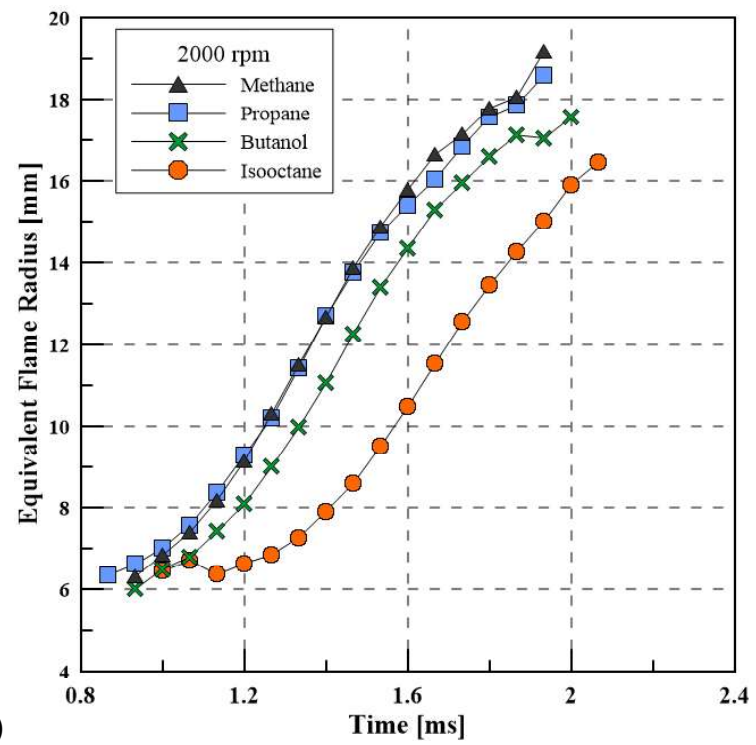

Figure 13. Mean flame radius evolution for all the mixtures at a) $1400 \mathrm{rpm}$ and b) $2000 \mathrm{rpm}$ [26]. 

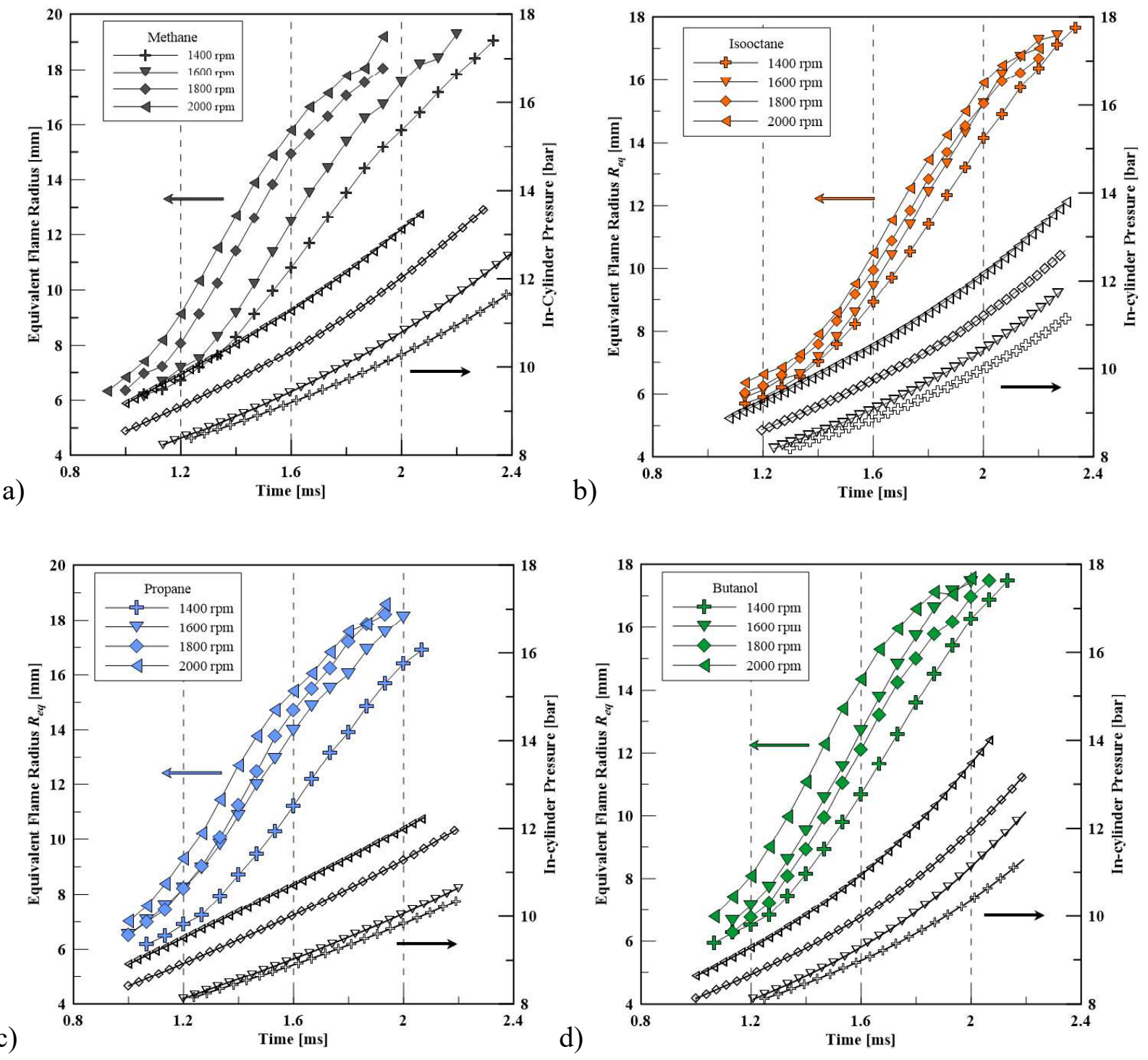

Figure 14. Flame radius (filled symbols) and in-cylinder pressure (empty symbols) evolutions at all the engine speeds for a) Methane, b) Iso-octane, c) Propane, d) Butanol.

\section{Flame Stretch Sensitivity}

Concerning the effect of engine speed on flame stretch sensitivity, the values of the slopes obtained from plots representing the flame propagation speed as a function of the global flame stretch in [26] are presented in Table 7. It can be seen that the flame stretch sensitivity ranking is 
the same as the Lewis number ranking and it is conserved whatever the engine speed or turbulence intensity except at $1800 \mathrm{rpm}$ where propane presents the highest stretch sensitivity.

When comparing the values obtained here to those obtained in the turbulent vessel, the sensitivities in the engine are lower probably because of the higher pressure in the engine which decreases the Markstein length. Then when looking at the differences between the tomographic results at $1200 \mathrm{rpm}$ and those from direct visualization at $1400 \mathrm{rpm}$, the stretch sensitivities are higher at $1400 \mathrm{rpm}$ than at $1200 \mathrm{rpm}$ which is at first sight consistent with u' effect on stretch sensitivities observed in the vessel with Table 3. However, as described in section 3.1, miescattering tomography measurements are planar whereas with direct visualization the threedimensional flame is projected in the plane of the piston. This implies a measurement bias on the flame area that leads to different values measured with the two optical techniques.

Besides when increasing the engine speed, this trend due to the u' effect is no longer so obvious with direct visualization and the effect of the engine speed on flame stretch sensitivity is not so clear-cut. If the values of Table 7 at $1400 \mathrm{rpm}$ are compared to those at $2000 \mathrm{rpm}$, the stretch sensitivity seems to globally decrease with the engine speed and this could be explained by the incylinder pressure increase with the engine speed as shown in Fig. 14. The pressure effect on the Markstein length may then be predominant compared to the turbulent intensity effect on the stretch sensitivity. Nonetheless, it is important to underline that no matter what the optical technique or the engine speed, the stretch sensitivity ranking between mixtures is maintained. 


\begin{tabular}{|c|c|c|c|c|c|}
\hline Engine speed & $\mathrm{u}^{\prime}$ & $\begin{array}{c}\text { Methane } \\
\text { Le }=0.99\end{array}$ & $\begin{array}{c}\text { Propane } \\
\text { Le }=1.76\end{array}$ & $\begin{array}{c}\text { Butanol } \\
\text { Le }=2.12\end{array}$ & $\begin{array}{c}\text { Iso-octane } \\
\text { Le =2.85 }\end{array}$ \\
\hline $1400 \mathrm{rpm}$ & $1.1 \mathrm{~m} / \mathrm{s}$ & 1.8 & 3.1 & 3.4 & 3.7 \\
\hline $1600 \mathrm{rpm}$ & $1.3 \mathrm{~m} / \mathrm{s}$ & 0.7 & 3.1 & 3.5 & 4.4 \\
\hline $1800 \mathrm{rpm}$ & $1.4 \mathrm{~m} / \mathrm{s}$ & 1.3 & 3.9 & 1.5 & 2.5 \\
\hline $2000 \mathrm{rpm}$ & $1.6 \mathrm{~m} / \mathrm{s}$ & 0.4 & 1.9 & 2.2 & 2.1 \\
\hline
\end{tabular}

Table 7. Arbitrary Flame stretch sensitivities [mm] [26].

\subsection{Conclusion on optical engine measurements}

The selection of mixtures based on laminar combustion at 1 bar and $400 \mathrm{~K}$ made it possible to focus on the stretch effect inside a Spark-Ignition engine. Different flame propagation behaviors were observed depending on the mixture used, mainly due to the different stretch sensitivities and degree of resistance to wrinkling. Finally it seems that the more stretch-sensitive (and/or difficult to wrinkle) the mixture is, the more delayed the combustion development is. The major result of this study is that by comparing the Markstein length measurements in laminar regime, trends concerning the combustion behavior of the mixture in the engine can be deduced.

\section{Engine Global Combustion Characteristics}

\subsection{Experimental set-up}

For each experiment on the optical engine, the in-cylinder pressure traces were acquired in order to calculate combustion duration by thermodynamic analysis. This made it possible to focus on the combustion phasing, which is a more global combustion characteristic directly linked to efficiency. To complete the study and obtain measurements in more realistic conditions, experiments were carried out in an all-metal single-cylinder engine whose operating specifications (intake pressure and temperature, ignition properties) are similar to those of the optical engine, as 
shown in Table 4. The two engines used for the experiments present similar running conditions but different geometrical properties such as displaced volume, compression ratio, stroke and bore. Moreover due to the different piston geometries (for the optical engine the piston is flat whereas for the all-metallic engine the piston has a bowl shape), the internal flow fields in the two engines are different and especially the tumble ratio, estimated close to 1 [52] for the optical engine and about 2.4 [53] for the all-metal one. For the all-metal engine as well as in the optical engine for the direct visualization study 100 consecutive firing cycles were processed. For the tomographic study in the optical engine, only 50 cycles were processed because of the dirt generated on the windows by the silicon seeding. As described in Table 4, both engines present the same ignition timing as well as similar intake pressure and temperature conditions thus enabling some comparisons regarding the combustion phasing. Regarding the injection system of the all-metal engine, fuel and air are injected in the intake pipe before the plenum. In the case of liquid fuels in the all-metal engine, the fuel passes through an evaporator before the plenum so that a homogeneous mixture is already obtained in the plenum. For both engines, the homogeneous mixture is then prepared in the intake.

Concerning the stability, the COV of the IMEP (covariance of the Indicated Mean Effective Pressure) was estimated for all the cases in both the optical and the metallic engine. The COV was globally less than $3 \%$ in all cases, indicating a good stability of the engines and low cycle-to-cycle variations.

\subsection{Lewis effect on combustion phasing}

The CA05 corresponding to the crank angle at which $5 \%$ of the mixture mass has burned was estimated for each condition (mixture and engine speed) and is shown versus the Lewis number in Figure 15 with an uncertainty of $+/-0.4 \mathrm{CAD}$ for all the fuels. It can be seen that the CA05 is 
linearly linked to the Lewis number. As the Lewis number increases, the combustion delay increases: for a Lewis number increase from 0.99 to 2.85 , there 5 CAD of difference. Consequently, flame stretch sensitivity has an impact on the global combustion phasing and development, confirmed also by the plot of CA10 and CA50 which verify the same linear evolution with $L e$ number.

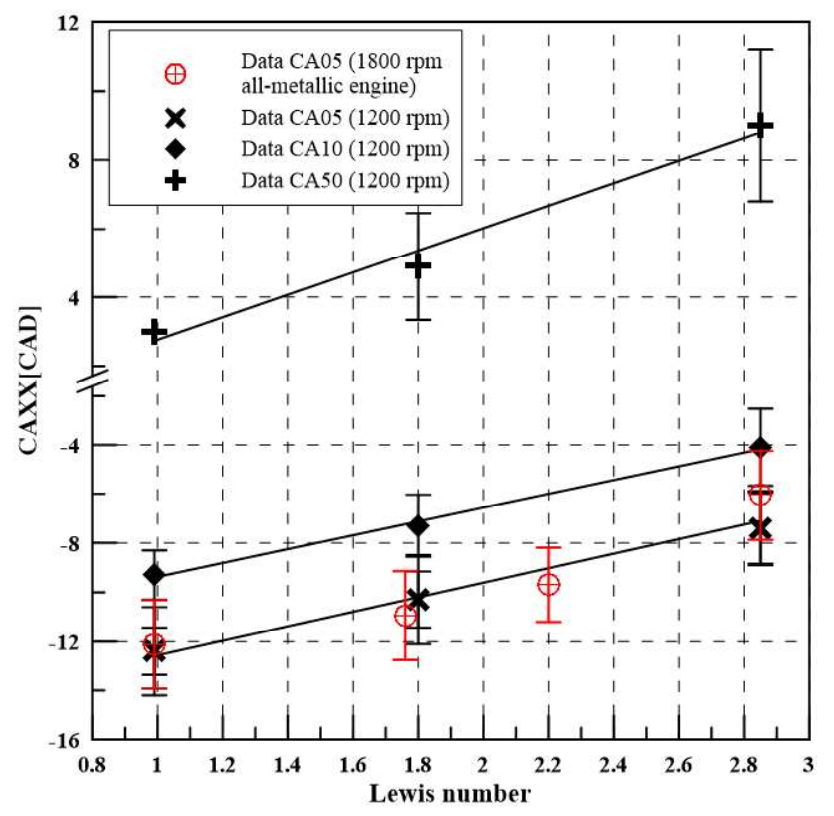

Figure 15. CAXX versus Lewis number for all cases.

Concerning the burnt gas residuals that can appear in the all-metal engine, they should not alter the comparison and the trends observed, since even if a small quantity of burnt gas residuals (maximum 5\%) can be considered in the all-metal engine, a previous study in laminar regime showed that dilution has little influence on the Markstein length [35]. 
4.3 Engine speed effect on combustion phasing

The effect of increasing the engine speed on the combustion phasing was also studied. Figure 16 plots CA05 as a function of engine regimes for all the mixtures. The ranking of the different mixtures in terms of CA05 is in agreement with the flame radius evolutions observed in Figure 14 and with the results of Aleiferis et al. [25]. When increasing the regime, the CA05 increases but depending on the fuel:

- There is a strong increase in the CA05 for iso-octane and butanol which are stretch-sensitive mixtures. This can be explained by their flame speed increase with the regime (Fig. 14. (b)) which is too low to compensate for the piston speed effect. The flame has less time to propagate and the combustion phasing cannot be maintained.

- For methane and propane flames which are less stretch-sensitive and easier to wrinkle, the CA05 increase with the engine speed is lower. The flame speed increase for those two mixtures (Fig. 14. (a)) seems to be sufficient to compensate for the piston speed effect and thereby maintain the phasing. 

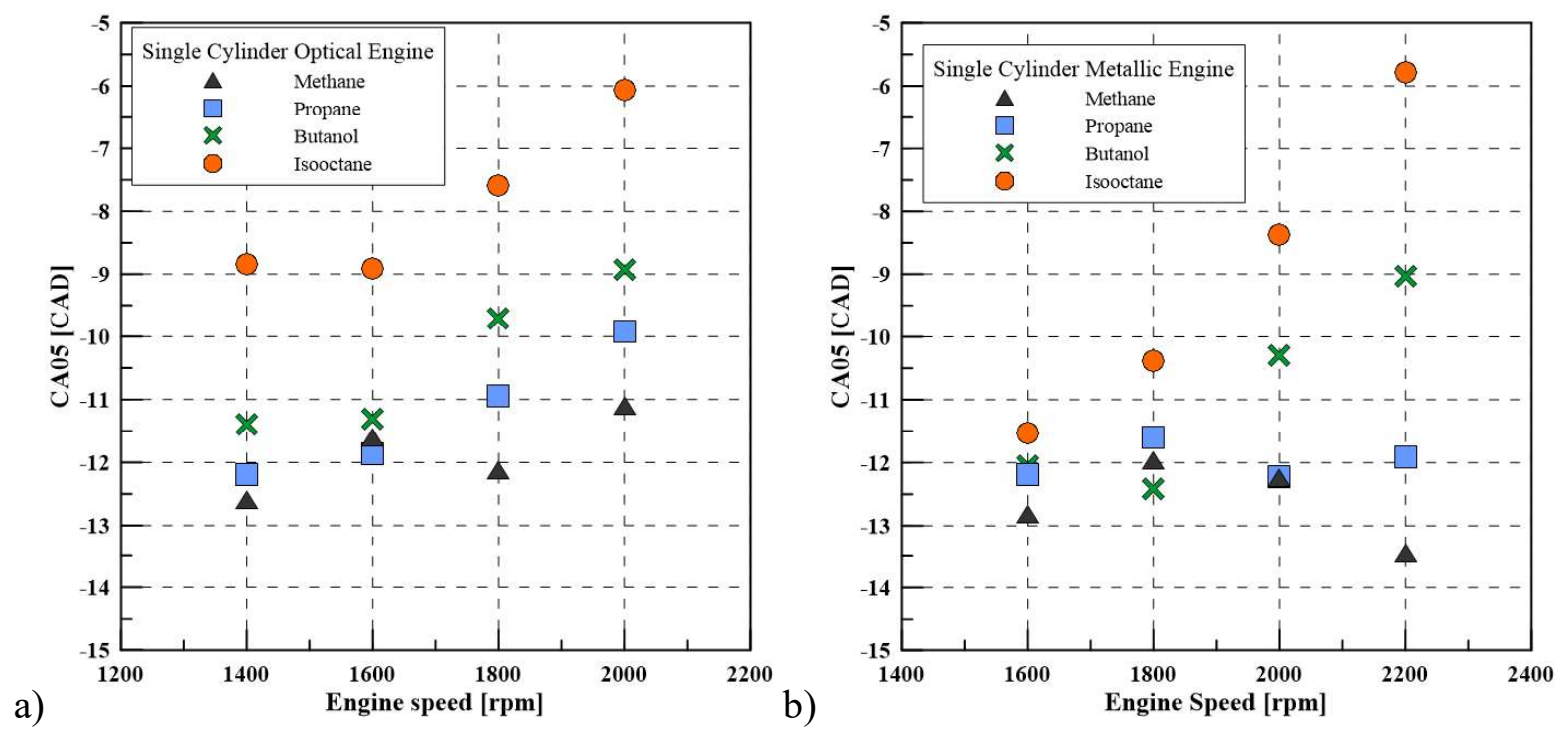

Figure 16. CA05 versus engine speed for a) in the optical engine (Renault J4S) and b) in the allmetal engine (PSA, EP6).

It is interesting to note that a similar CA05 evolution with the regime is obtained in a single cylinder all-metal engine with very different internal flow motion and specificities than the optical one (see characteristics in Table 8). It can therefore be concluded that the flame stretch sensitivity has an impact on the combustion phasing regardless of the engine, the compression ratio, or the internal aerodynamics and that the flame stretch response of the mixture affects the efficiency. This observation provides evidence for taking flame stretch sensitivity into account in combustion models for SI engines.

\section{Conclusion}

In this paper, the impact of flame stretch on flame propagation was investigated using various experimental devices: a spherical vessel in laminar and turbulent conditions, and both optical and all-metal Spark-Ignition engines. The study focused on how the fuel properties related to flame stretch sensitivity can impact the engine performance. 
Different lean mixtures were selected from laminar flame propagations (at 1 bar, $400 \mathrm{~K}$ ), with the following criterion: similar unstretched flame speeds but different responses to stretch, indicated by different Markstein lengths and Lewis numbers. The selected mixtures can be ranked from the most to the least stretch-sensitive as follows: iso-octane, propane, butanol, methane.

The combustions of the mixtures were then studied in turbulent conditions at 1 bar, $400 \mathrm{~K}$ in the spherical vessel by using Mie-scattering tomography. Different flame radius evolutions were observed depending on the mixture, leading to different flame speeds. Iso-octane was the slowest mixture while methane was the fastest. Moreover the flame speed increased continuously for all the mixtures due to several phenomena: the decrease in flame stretch with propagation combined with the positive Markstein lengths of the three mixtures and the response time of the flame to turbulence. Regarding the stretch response of the mixtures, different behaviors were shown on the flame speed versus flame stretch plots. These differences seem to be mainly due to the Markstein length of the mixtures and the ability of their flame to wrinkle, indicated by their Lewis numbers.

Experiments were then carried out in an optical S.I. engine. The different flame propagation behaviors depending on the mixtures were also visible despite the high in-cylinder pressure and temperature and their increase during combustion itself. The slope ranking of the flame speed versus flame stretch curves is also the same regardless of the experimental set-up or the conditions (pressure, temperature, turbulence). This means that the flame stretch sensitivity ranking is maintained from laminar combustion to engine combustion. This is an important result because it reveals that the Markstein length measurements, obtained in laminar combustion conditions even at lower pressure and temperature than an engine can help to predict comparatively fuel behavior in terms of combustion performance in the engine. The engine speed affects the flame development depending on the mixture used itself and its flame stretch sensitivity. However, the stretch 
sensitivity ranking of the mixtures is again maintained regardless of the engine speed or the turbulence intensity as was observed in the spherical vessel. Finally a linear relationship was found to link the combustion phasing and the stretch sensitivity of the mixtures represented by the Lewis number, for different mixtures and engine regimes.

The effect of Markstein length on both laminar and turbulent flame speeds is already well covered by the literature. However its impact inside a Spark-Ignition engine on the combustion phasing which is linked to the yield of the engine has never been studied until now. The study has attempted to cover all the aspects of the flame stretch sensitivity effects by increasing gradually the complexity of the experiments thus enabling the effects of turbulence, of pressure and temperature, of the engine aerodynamics and of the cycle-to-cycle variations to be included step by step. The results obtained in the all-metal engine are then strengthened by the analysis done in the vessel and in the optical engine. To conclude, this study reveals the impact of the Markstein lengths in SparkIgnition engines thanks to:

- a mixture selection that enables to focus on the effect of the various flame stretch responses of different mixtures;

- a detailed analysis of the behavior of those mixtures in a turbulent vessel where the effect of the turbulent intensity was investigated and is in agreement with the literature;

- a study in an optical engine showing that the effect of flame stretch responses on the flame propagation observed in the turbulent vessel is also visible in the engine combustion chamber even with the higher pressure and temperature;

- a depth analysis of the engine speed effect on the flame stretch responses of the mixtures that brings out the effects of pressure and turbulent intensity increases on the turbulent flame speed; 
- the measurements of the combustion phasing in both optical and all-metal engines that enables the results observed to be extrapolated to other kinds of Spark-ignition engines. The conclusions drawn for the all-metal engine are also validated by the results obtained with all the experimental devices and diagnostics used in this study.

Finally, this study has demonstrated that the unstretched laminar burning speed is not sufficient when evaluating a fuel for engine use. The flame stretch sensitivity of the mixtures has also to be considered. The integration of the laminar flame speed dependence on flame stretch in CFD models has to be considered as a future issue and not only the unstretched values as in most current models, based on the use of a stretch factor and the unstretched laminar burning speed.

In future work, it will be important to determine whether the flame stretch sensitivity effect is still visible when the engine runs in optimal conditions to provide the highest efficiency (optimal ignition timing, higher intake pressure, etc.) but also in the case of a Stratified GDI mode and with EGR

\section{Acknowledgements}

This work has been made possible thanks to the financial support of Total S.A and the Association Nationale de la Recherche Technique, France through a CIFRE fellowship (\# 2011/1089).

\section{References}

[1] J. Vancoillie, J. Demuynck, L. Sileghem, M. Van De Ginste, S. Verhelst, L. Brabant, et al., The potential of methanol as a fuel for flex-fuel and dedicated spark-ignition engines, Appl. Energy. 102 (2013) 140-149. doi:10.1016/j.apenergy.2012.05.065.

[2] X. Wu, Q. Li, J. Fu, C. Tang, Z. Huang, R. Daniel, et al., Laminar burning characteristics of 2,5-dimethylfuran and iso-octane blend at elevated temperatures and pressures, Fuel. 95 
(n.d.) 234-240. http://www.sciencedirect.com/science/article/pii/S0016236111007526.

[3] X. Wu, Z. Huang, X. Wang, C. Jin, C. Tang, L. Wei, et al., Laminar burning velocities and flame instabilities of 2,5-dimethylfurane-air mixtures at elevated pressures, Combust. Flame. 158 $539-546$. http://www.sciencedirect.com/science/article/pii/S0010218010002890.

[4] P. Brequigny, G. Dayma, F. Halter, C. Mounaïm-Rousselle, T. Dubois, P. Dagaut, Laminar burning velocities of premixed nitromethane/air flames: An experimental and kinetic modeling study, Proc. Combust. Inst. 35 (2014) 703-710. doi:10.1016/j.proci.2014.06.126.

[5] S. Richard, O. Colin, O. Vermorel, A. Benkenida, C. Angelberger, D. Veynante, Towards large eddy simulation of combustion in spark ignition engines, Proc. Combust. Inst. 31 (2007) 3059-3066. doi:10.1016/j.proci.2006.07.086.

[6] S. Bougrine, S. Richard, O. Colin, D. Veynante, Fuel Composition Effects on Flame Stretch in Turbulent Premixed Combustion: Numerical Analysis of Flame-Vortex Interaction and Formulation of a New Efficiency Function, Flow, Turbul. Combust. (2014) 1-23. doi:10.1007/s10494-014-9546-4.

[7] N. Peters, The turbulent burning velocity for large-scale and small-scale turbulence, J. Fluid Mech. 384 (1999) 107-132. doi:http://dx.doi.org/10.1017/S0022112098004212.

[8] T. Lucchini, L. Cornolti, G. Montenegro, G. D'Errico, A Comprehensive Model to Predict the Initial Stage of Combution in SI Engines, SAE Tech. Pap. (2013). doi:10.4271/2013-011087.

[9] R.N. Dahms, M.C. Drake, T.D. Fansler, T.-W. Kuo, N. Peters, Understanding ignition processes in spray-guided gasoline engines using high-speed imaging and the extended 
spark-ignition model SparkCIMM Part B: Importance of molecular fuel properties in early flame front propagation, Combust. Flame. $158 \quad$ (2011) 2245-2260. doi:10.1016/j.combustflame.2011.04.003.

[10] R.N. Dahms, M.C. Drake, T.D. Fansler, T.-W.W. Kuo, N. Peters, Understanding ignition processes in spray-guided gasoline engines using high-speed imaging and the extended spark-ignition model SparkCIMM. Part A: Spark channel processes and the turbulent flame front propagation, Combust. Flame. $158 \quad$ (2011) 2245-2260. doi:10.1016/j.combustflame.2011.03.012.

[11] S.M. Candel, T.J. Poinsot, Flame Stretch and the Balance Equation for the Flame Area, Combust. Sci. Technol. 70 (1990) 1-15. doi:10.1080/00102209008951608.

[12] F.A. Williams, A review of some theretical considerations of turbulent flame structure, in: Agard Conf. Procedings No. 164, 1975.

[13] B. Karlovitz, D.W. Denniston, D.H. Knapschaefer, F.E. Wells, Studies on Turbulent flames, Symp. Combust. 4 (1953) 613-620. doi:10.1016/S0082-0784(53)80082-2.

[14] G.H. Markstein, Non-steady Flame Propagation, Pergamon Press, 1964.

[15] P. Clavin, Dynamic behavior of premixed flame fronts in laminar and turbulent flows, Prog. Energy Combust. Sci. 11 (1985) 1-59. doi:10.1016/0360-1285(85)90012-7.

[16] A.P. Kelley, C.K. Law, Nonlinear effects in the extraction of laminar flame speeds from expanding spherical flames, Combust. Flame. $156 \quad$ (2009) 1844-1851. doi:10.1016/j.combustflame.2009.04.004.

[17] Z. Chen, Y. Ju, Theoretical analysis of the evolution from ignition kernel to flame ball and planar flame, Combust. Theory Model. $11 \quad$ (2007) 427-453. 
http://dx.doi.org/10.1080/13647830600999850.

[18] F. Halter, T. Tahtouh, C. Mounaïm-Rousselle, Nonlinear effects of stretch on the flame front propagation, $\quad$ Combust. $\quad$ Flame. $\quad 157 \quad$ (2010) doi:10.1016/j.combustflame.2010.05.013.

[19] D. Bradley, R.A. Hicks, M. Lawes, C.G.W. Sheppard, R. Woolley, The Measurement of Laminar Burning Velocities and Markstein Numbers for Iso-octane-Air and Iso-octane-nHeptane-Air Mixtures at Elevated Temperatures and Pressures in an Explosion Bomb, Combust. Flame. 115 (1998) 126-144. doi:10.1016/S0010-2180(97)00349-0.

[20] D. Bradley, M. Lawes, M.S. Mansour, Explosion bomb measurements of ethanol-air laminar gaseous flame characteristics at pressures up to 1.4 MPa, Combust. Flame. 156 (2009) 14621470. doi:10.1016/j.combustflame.2009.02.007.

[21] A.P. Kelley, A.J. Smallbone, D.L. Zhu, C.K. Law, Laminar flame speeds of C5 to C8 nalkanes at elevated pressures: Experimental determination, fuel similarity, and stretch sensitivity, Proc. Combust. Inst. 33 (2011) 963-970. doi:10.1016/j.proci.2010.06.074.

[22] R.G. Abdel-Gayed, D. Bradley, M. Lawes, Turbulent Burning Velocities: A General Correlation in Terms of Straining Rates, Proc. R. Soc. London. A. Math. Phys. Sci. . 414 (1987) 389-413. doi:10.1098/rspa.1987.0150.

[23] D. Bradley, M.Z. Haq, R.A. Hicks, T. Kitagawa, M. Lawes, C.G.W. Sheppard, et al., Turbulent burning velocity, burned gas distribution, and associated flame surface definition, Combust. Flame. 133 (2003) 415-430. doi:10.1016/S0010-2180(03)00039-7.

[24] L. Gillespie, M. Lawes, C.G.W. Sheppard, R. Woolley, Aspects of Laminar and Turbulent Burning Velocity Relevant to SI Engines Reprinted From: Advances in Combustion, 
$(2000)$

[25] P.G. Aleiferis, J. Serras-Pereira, D. Richardson, Characterisation of flame development with ethanol, butanol, iso-octane, gasoline and methane in a direct-injection spark-ignition engine, Fuel. 109 (2013) 256-278. doi:10.1016/j.fuel.2012.12.088.

[26] P. Brequigny, C. Mounaïm-Rousselle, F. Halter, B. Moreau, T. Dubois, Impact of Fuel Properties and Flame Stretch on the Turbulent Flame Speed in Spark-Ignition Engines, SAE Tech. Pap. (2013). doi:10.4271/2013-24-0054.

[27] P. Brequigny, F. Halter, C. Mounaïm-Rousselle, B. Moreau, T. Dubois, Thermodiffusive Effect on the Flame Development in Lean Burn Spark Ignition Engine, SAE Tech. Pap. (2014). doi:10.4271/2014-01-2630.

[28] H.G. Weller, G. Tabor, A.D. Gosman, C. Fureby, Application of a flame-wrinkling les combustion model to a turbulent mixing layer, Symp. Combust. 27 (1998) 899-907. doi:10.1016/S0082-0784(98)80487-6.

[29] M. Metghalchi, J.C. Keck, Burning velocities of mixtures of air with methanol, isooctane, and indolene at high pressure and temperature, Combust. Flame. 48 (1982) 191-210. http://www.sciencedirect.com/science/article/pii/0010218082901274.

[30] Ö. Gülder, Correlations of Laminar Combustion Data for Alternative S.I. Engine Fuels, SAE Tech. Pap. (1984). doi:10.4271/841000.

[31] I. Han, K.Y. Huh, Roles of displacement speed on evolution of flame surface density for different turbulent intensities and Lewis numbers in turbulent premixed combustion, Combust. Flame. 152 (2008) 194-205. doi:10.1016/j.combustflame.2007.10.003.

[32] R.G. Abdel-Gayed, D. Bradley, M.N. Hamid, M. Lawes, Lewis number effects on turbulent 
burning velocity, Symp. Combust. 20 (1985) 505-512. doi:10.1016/S0082-0784(85)805397.

[33] B. Renou, A. Boukhalfa, An Experimental Study of Freely Propagating Premixed Flames at Various Lewis Numbers, Combust. Sci. Technol. 162 (2001) 347-370. doi:10.1080/00102200108952148.

[34] B. Galmiche, N. Mazellier, F. Halter, F. Foucher, Turbulence characterization of a highpressure high-temperature fan-stirred combustion vessel using LDV, PIV and TR-PIV measurements, Exp. Fluids. 55 (2013) 1-20. doi:10.1007/s00348-013-1636-x.

[35] B. Galmiche, F. Halter, F. Foucher, Effects of high pressure, high temperature and dilution on laminar burning velocities and Markstein lengths of iso-octane/air mixtures, Combust. Flame. 159 (2012) 3286-3299. doi:10.1016/j.combustflame.2012.06.008.

[36] G. Broustail, F. Halter, P. Seers, G. Moréac, C. Mounaïm-Rousselle, Experimental determination of laminar burning velocity for butanol/iso-octane and ethanol/iso-octane blends for different initial pressures, Fuel. $106 \quad$ (2013) 310-317. doi:10.1016/j.fuel.2012.10.066.

[37] G. Broustail, P. Seers, F. Halter, G. Moréac, C. Mounaim-Rousselle, Experimental determination of laminar burning velocity for butanol and ethanol iso-octane blends, Fuel. 90 (2011) 1-6. http://www.sciencedirect.com/science/article/pii/S0016236110004928.

[38] D. Bradley, C.G.W. Sheppard, I.M. Suardjaja, R. Woolley, Fundamentals of high-energy spark ignition with lasers, Combust. Flame. $138 \quad$ (2004) 55-77. http://www.sciencedirect.com/science/article/pii/S0010218004000914.

[39] T. Tahtouh, F. Halter, C. Mounaïm-Rousselle, Measurement of laminar burning speeds and 
Markstein lengths using a novel methodology, Combust. Flame. 156 (2009) 1735-1743. http://www.sciencedirect.com/science/article/pii/S0010218009000935.

[40] R.J. Kee, F.M. Rupley, J.A. Miller, CHEMKIN-II: A FORTRAN Chemical Kinetics Package for the Analysis of Gas-Phase Chemical Kinetics, Sandia National Laboratories, Albequerque, NM, 1989. citeulike-article-id:9062777.

[41] X.J.J. Gu, M.Z.Z. Haq, M. Lawes, R. Woolley, Laminar burning velocity and Markstein lengths of methane-air mixtures, Combust. Flame. 121 (2000) 41-58. doi:10.1016/S00102180(99)00142-X.

[42] C. Tang, J. Zheng, Z. Huang, J. Wang, Study on nitrogen diluted propane-air premixed flames at elevated pressures and temperatures, Energy Convers. Manag. 51 (2010) 288-295. doi:10.1016/j.enconman.2009.09.024.

[43] G.P. Smith, D.M. Golden, M. Frenklach, N.W. Moriarty, B. Eiteneer, M. Goldenberg, et al., GRI-Mech 3.0, (n.d.).

[44] H. Wang, X. You, A. V. Joshi, S.G. Davis, A. Laskin, F. Egolfopoulos, et al., USC Mech Version II. High-Temperature Combustion Reaction Model of H2/CO/C1-C4 Compounds., (2007). http://ignis.usc.edu/USC_Mech_II.htm.

[45] C. Hasse, M. Bollig, N. Peters, H.A. Dwyer, Quenching of laminar iso-octane flames at cold walls, Combust. Flame. 122 (2000) 117-129. doi:10.1016/S0010-2180(00)00107-3.

[46] B. Renou, A. Boukhalfa, D. Puechberty, M. Trinité, Effects of stretch on the local structure of freely propagating premixed low-turbulent flames with various lewis numbers, Symp. Combust. 27 (1998) 841-847. doi:10.1016/S0082-0784(98)80480-3.

[47] S. Chaudhuri, A. Saha, C.K. Law, On flame-turbulence interaction in constant-pressure 
expanding flames, Proc. Combust. Inst. $35 \quad$ (2015) 1331-1339. doi:10.1016/j.proci.2014.07.038.

[48] F. Halter, C. Chauveau, I. Gökalp, D. Veynante, Analysis of flame surface density measurements in turbulent premixed combustion, Combust. Flame. 156 (2009) 657-664. doi:10.1016/j.combustflame.2008.11.016.

[49] D. Veynante, G. Lodato, P. Domingo, L. Vervisch, E. Hawkes, Estimation of threedimensional flame surface densities from planar images in turbulent premixed combustion, Exp. Fluids. 49 (2010) 267-278. doi:10.1007/s00348-010-0851-y.

[50] M. Zhang, J. Wang, W. Jin, Z. Huang, H. Kobayashi, L. Ma, Estimation of 3D flame surface density and global fuel consumption rate from 2D PLIF images of turbulent premixed flame, Combust. Flame. 162 (2015) 2087-2097. doi:10.1016/j.combustflame.2015.01.007.

[51] R.J. Moffat, Describing the uncertainties in experimental results, Exp. Therm. Fluid Sci. 1 (1988) 3-17. doi:10.1016/0894-1777(88)90043-X.

[52] B. Galmiche, Caractérisation expérimentale des flammes laminaires et turbulentes en expansion, Université d'Orléans, 2014.

[53] M. Lawes, M.P. Ormsby, C.G.W. Sheppard, R. Woolley, The turbulent burning velocity of iso-octane/air mixtures, Combust. Flame. $159 \quad$ (2012) 1949-1959. http://www.sciencedirect.com/science/article/pii/S0010218011004329.

[54] O. Pajot, C. Mounaïm-Rousselle, Instantaneous Flow Field Effects on the Flame Kernel in S.I.Engine by Simultaneous Optical Diagnostics, SAE Tech. Pap. (2000). doi:10.4271/200001-1796.

[55] Zhou, J., S. Richard, C. Mounaïm-Rousselle, F. Foucher, Effects of Controlling Oxygen 
Concentration on the Performance, Emission and Combustion Characteristics in a Downsized SI Engine, SAE Tech. Pap. (2013). doi:10.4271/2013-24-0056.

[56] T. Tahtouh, F. Halter, E. Samson, C. Mounaïm-Rousselle, Effects of hydrogen addition under lean and diluted conditions on combustion characteristics and emissions in a sparkignition engine, Int. J. Engine Res. . 12 (2011) 466-483. doi:10.1177/1468087411409309.

[57] T. Tahtouh, Les effets combinés de l'hydrogène et de la dilution dans un moteur à allumage commandé, Univ. Orleans, 2010. http://www.theses.fr/2010ORLE2052/document.

[58] O. Pajot, Etude expérimentale de l'influence de l'aérodynamique sur le comportement et la structure du front de flamme dans les conditions d'un moteur à allumage commandé, Université d'Orléans, 2000.

[59] J.B. Heywood, Internal combustion engine fundamentals, McGraw-Hill, 1988.

[60] S.M. Sarathy, S. Vranckx, K. Yasunaga, M. Mehl, P. Oßwald, W.K. Metcalfe, et al., A comprehensive chemical kinetic combustion model for the four butanol isomers, Combust. Flame. 159 (2012) 2028-2055. doi:http://dx.doi.org/10.1016/j.combustflame.2011.12.017.

[61] G. Rozenchan, D.L. Zhu, C.K. Law, S.D. Tse, Outward propagation, burning velocities, and chemical effects of methane flames up to 60 ATM, Proc. Combust. Inst. 29 (2002) 14611470. doi:10.1016/S1540-7489(02)80179-1.

[62] G. Jomaas, X.L. Zheng, D.L. Zhu, C.K. Law, Experimental determination of counterflow ignition temperatures and laminar flame speeds of C2-C3 hydrocarbons at atmospheric and elevated pressures, Proc. Combust. Inst. $30 \quad$ (2005) 193-200. doi:10.1016/j.proci.2004.08.228. 